\title{
METALLOGRAPHIC ETCHING REAGENTS: \\ II. FOR COPPER ALLOYS, NICKEL, AND THE ALPHA ALLOYS OF NICKEL
}

\author{
By Henry S. Rawdon and Marjorie G. Lorentz
}

\begin{abstract}
This investigation constitutes the second part of the general study of metallographic etching reagents at this Bureau. The following were used as typical materials for etching: Copper alloys, including all the typical copper-zinc alloys, bronze and aluminum bronze, nickel and the $\alpha$ alloys of nickel, monel metal, cupro-nickel, and nickel brass.

Experimental results are given to show the importance of films varying in thickness upon the different crystals in a metallographic specimen in producing a "contrast etch pattern." This is clearly shown by separating the filming and the etching operations, both sulphide and oxide films being used.

The $\alpha$ copper alloys resemble copper in their general behavior upon etching. Aluminum bronze was found to be the most unsatisfactory of such alloys of copper to etch.

Nickel is etched with considerable difficulty. Strong oxidizing acids, such as nitric, or other acids to which oxidizing agents have been added may be used, but there is usually considerable pitting of the surface and a very noticeable lack of contrast in the resulting etch pattern. Concentrated hydrochloric acid, however, gives excellent results in both these respects. Monel metal and cupro-nickel resemble nickel in their etching characteristics, though they are etched more readily. The nickel brasses are much more like the brasses and bronzes and are readily etched by reagents used for these alloys.

Copper alloys, like copper, are readily etched by ammoniacal, acid, and some neutral solutions which otherwise would have only a slight effect upon them provided a stream of oxygen is passed through the solution while the specimen is immersed. Nickel, cupro-nickel, and monel metal are not materially affected in the rate of etching by the use of oxygen gas.
\end{abstract}

\section{CONTENTS}

Page

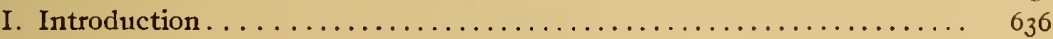

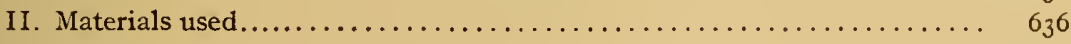

III. Results. . . . . . . . . . . . . . . . . . . . . . $6 \ldots \ldots \ldots \ldots$

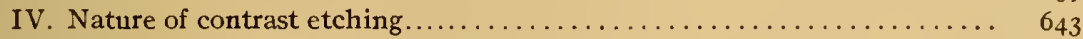

V. Etching characteristics of copper alloys................... 646

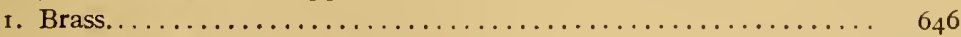

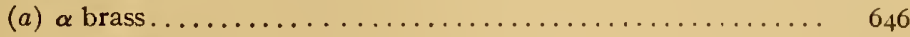

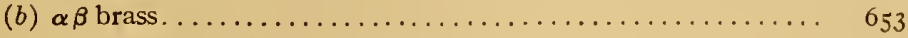

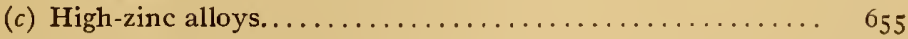

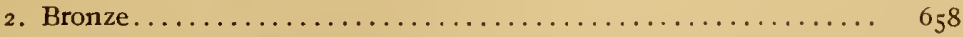

3. Aluminum bronze . . . . . . . . . . . . . . . . . . . $6_{5} 8$

VI. Etching characteristics of nickel and of $\alpha$ nickel alloys . . . . . . . $6_{5} 8$

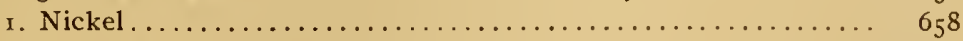

2. Nickel alloys. . . . . . . . . . . . . . . . . . . . . . 666

VII. Effect of oxygen upon the rate of etching . . . . . . . . . . . . 673

VIII. Summary ................................... 075 


\section{INTRODUCTION}

The work herein described forms part of the general investigation of metallographic etching reagents in progress at the Bureau of Standards. In a previous article ${ }^{1}$ the authors summarized the results obtained with typical etching regents when copper was used as the metal which was etched. The results reported below were obtained in the extension of this investigation to the important industrial alloys of copper, the brasses and bronzes, to nickel, and to the common nickel-rich alloys. Since the present work was a direct continuation of the former study, the general method of investigation was similar to that previously employed. In addition to the reagents of the previous investigation certain others which were found to be particularly suited to some of the new materials were also used. The results obtained with copper suggested strongly the importance of oxidation in the successful etching of metallographic specimens. It was shown that most of the metallographic etching reagents used for etching copper and its alloys are oxidizing in their nature, the efficiency of the reagent depending largely upon this characteristic feature of the solution. Reagents which have at best only a very slight effect upon copper can be made to etch fairly readily either by passing oxygen through the liquid while the specimen is immersed or by adding an oxidizing agent. The character of the etched surface produced-that is, whether of the plain or of the contrast type-depends almost entirely upon the results of the oxidation which aids and accompanies the solution of the metal. In general, the results obtained in the present investigation with the typical copper-rich alloys chosen serve to confirm and to substantiate the conclusions reached in the former study. The alloys containing nickel are usually considerably more resistant to etching reagents than are the alloys of copper. This is particularly true for nickel itself, which is often satisfactorily etched only with extreme difficulty.

\section{MATERIALS USED}

The alloys which were used to illustrate the action of the different typical etching reagents prepared are listed in Table $\mathrm{I.}^{2}$

\footnotetext{
${ }^{1}$ Henry S. Rawdon and Marjorie G. Lorentz, Metallographic etching reagents: I, for copper, B. S. Sci, Papers No. 399, 1920.

2 Most of the rolled copper alloys were furnished for this investigation by W. H. Bassett, technical superintendent American Brass Co., and W. B. Price, chief chemist, Scovill Manufacturing Co., Waterhury, Conn. The nickel and the nickel-rich alloys were furnished by P. D. Merica, director of research, International Nickel Co., and by the Driver-Harris Co. The help thus given is here acknowledged.
} 


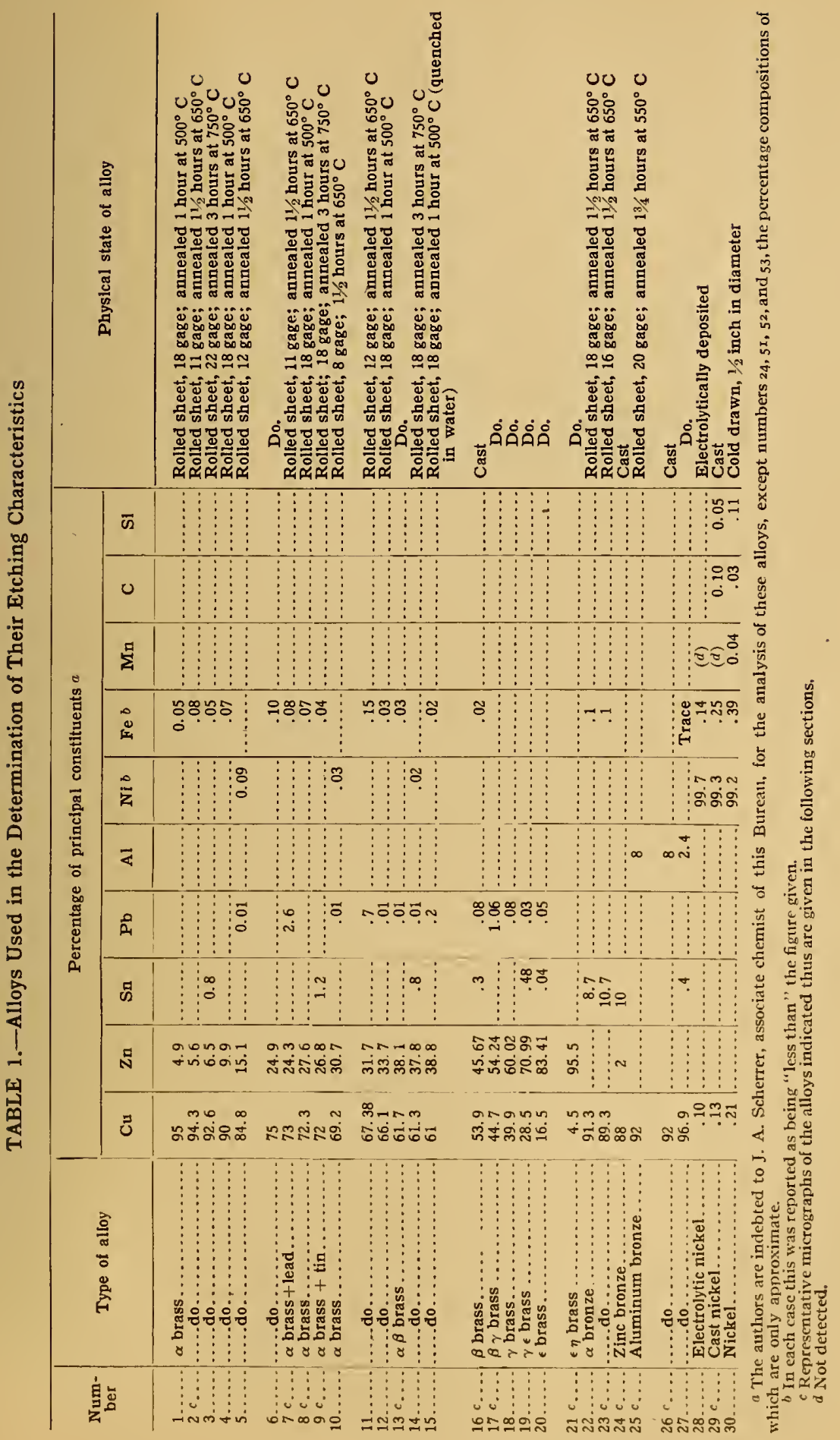




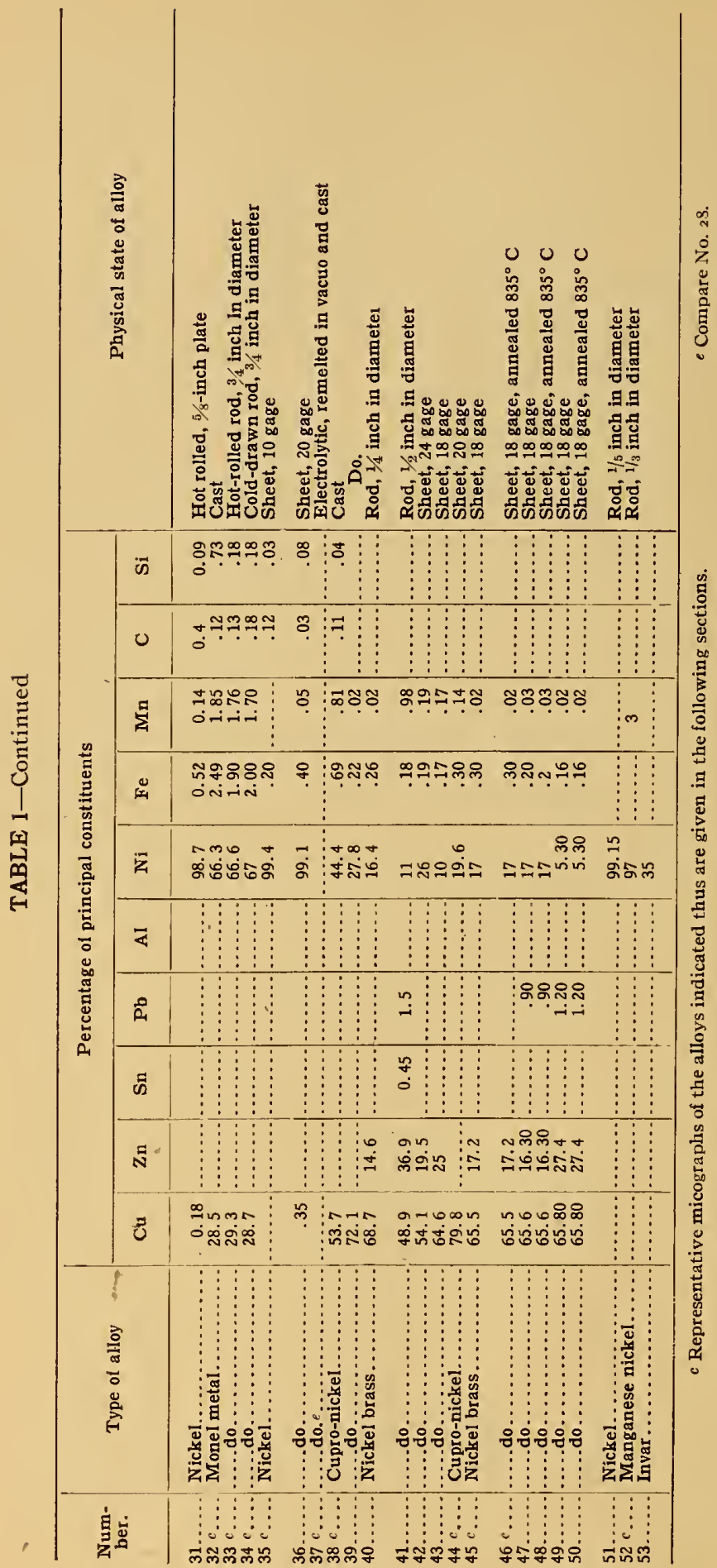


A great many of the industrially used brasses and bronzes are of relatively simple microstructure, inasmuch as they consist of only one constituent. For this reason several copper-zinc alloys with zinc content greater than that of industrial brasses were prepared. Several of the zinc-rich brasses are of a duplex structure, and thus illustrate the etching characteristics of alloys containing constituents which differ considerably in their electrochemical properties.

In the study of the nickel alloys only the industrially important $\alpha$ alloys were considered. The group of nickel-chromium alloys, though of very considerable importance from an industrial viewpoint, was not considered in this investigation. It is very probable that their characteristic structural features result from other conditions besides the nickel or chromium content. The various types of etching reagents employed are listed in Table 2.

TABLE 2.-Etching Reagents Used

\begin{tabular}{|c|c|c|}
\hline $\begin{array}{l}\text { Num- } \\
\text { ber }\end{array}$ & Reagent & Nature of etching soiution \\
\hline & $\begin{array}{l}10 \text { volumes concentrated ammonium hydroxide and } 1 \text { voiume } \\
\text { hydrogen peroxide ( } 3 \text { per cent solution) }\end{array}$ & Ammoniacai oxidizing solution \\
\hline & $\begin{array}{l}2 \text { volumes concentrated ammonium hydroxide and } 3 \text { volumes } \\
\left.\text { potassium permanganate solution ( } 4 \text { g per } 1000 \mathrm{~cm}^{3} \text { water }\right)\end{array}$ & Do. \\
\hline & $\begin{array}{l}1 \text { volume sulphuric acid ( } \mathrm{sp} \text {. gr. } 1.84 \text { ) and } 10 \text { volumes hydro- } \\
\text { gen peroxide ( } 3 \text { per cent solution) }\end{array}$ & Acid oxidizing solution \\
\hline & $\begin{array}{l}1 \text { volume sulphuric acid (sp.gr. } 1.84 \text { ) and } 5 \text { volumes saturated } \\
\text { solution of potassium dichromate }\end{array}$ & Do. \\
\hline & $\begin{array}{l}1 \text { voiume suiphuric acid (sp. gr. } 1.84 \text { ) and } 5 \text { volumes potas- } \\
\text { sium permanganate soiution }\left(4 \mathrm{~g} \text { per } 1000 \mathrm{~cm}^{3} \text { water) }\right.\end{array}$ & Do. \\
\hline & 10 per cent aqueous solutlon of ammonium persuiphate.... & Do. \\
\hline & 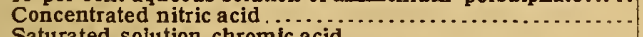 & Oxidizing acid \\
\hline & Saturated solution chromic acid $\ldots \ldots \ldots \ldots \ldots \ldots \ldots \ldots \ldots \ldots$ & Do. \\
\hline & $\begin{array}{l}10 \mathrm{~g} \text { ferric chioride, } 30 \mathrm{~cm}^{3} \text { hydrochloric acid (sp. gr. 1.19), } \\
120 \mathrm{~cm}^{3} \text { water }\end{array}$ & Acid oxidizing solution \\
\hline 10. & 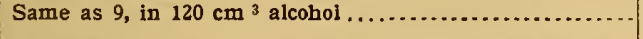 & Do. \\
\hline 11. & $\begin{array}{l}5 \mathrm{~g} \text { copper }=\text { ammonium chioride, } 120 \mathrm{~cm}^{3} \text { water, concentrated } \\
\text { ammonium hydroxide added until precipitate which forms } \\
\text { redissolves }\end{array}$ & Electrochemical action \\
\hline & 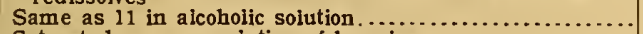 & Do. \\
\hline & 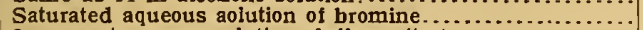 & Oxidizing solution \\
\hline & 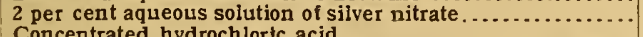 & Electrochemical action \\
\hline 15. & $\begin{array}{l}\text { Concentrated hydrochloric acid } \ldots . \ldots \ldots \ldots \ldots \ldots \\
\text { Nitric acid +acetic acid; } 50 \text { per cent nitric acid, } 25 \text { per cent }\end{array}$ & $\begin{array}{l}\text { Nonoxidizing acid } \\
\text { Oxidizing acid }\end{array}$ \\
\hline & $\begin{array}{l}\text { glacial acetic acid, } 25 \text { per cent water } \\
\text { Concentrated ammonium hydroxide and oxygen } \ldots \ldots \ldots \ldots\end{array}$ & Oxidation and an ammoniacal sol- \\
\hline & 10 per cent sulphuric acid and oxygen.... & $\begin{array}{l}\text { vent } \\
\text { Oxidation and an acid soivent }\end{array}$ \\
\hline & Ammonium chloride and oxygen $\ldots \ldots \ldots$ & Neutral salt solution and oxidation \\
\hline
\end{tabular}

\section{RESULTS}

One of the limitations in an investigation like the present one, in which the records are obtained almost entirely by means of micrographs, is the difficulty of concisely summarizing these results. The reproduction of all of the micrographs illustrating the results obtained for the different alloys with each of the etch- 
ing methods used is out of the question. For this reason there is given in Table 3 a resume of the general action of the different etching reagents upon the various alloys used. The following symbols have been employed for the purpose: e, excellent; g, good; f, fair; p, poor; $n$, no action. This forms the first letter of the key. The general nature of the etching action - that is, whether results of the contrast or of the plain type were obtained-has been indicated by $\mathrm{c}$ or $\mathrm{p}$ as the second letter of the key. The numerals show the approximate etching period required, in seconds, unless indicated otherwise. Although in the majority of cases the etching period was determined quite accurately, the figures given should be regarded as approximate only for the material in general. In some cases, particularly for nickel, the etching period was found to vary in a manner which could not be accounted for easily. After a specimen had been etched once satisfactorily, the etching period for subsequent etching was usually considerably less than at first. Further details concerning the various reagents and their action upon different alloys are given in some of the following sections.

Since the greater number by far of examinations of microstructure carried out are made at magnifications in the neighborhood of 100 diameters, this value was selected as standard for the examinations to be made in this investigation. Examinations at high magnifications are usually made for a very special purpose, and the specimen must be etched accordingly. The conclusions and opinions expressed in the following sections do not necessarily hold in all cases for examinations at high magnifications. 


\begin{tabular}{|c|c|c|c|c|c|c|}
\hline- & 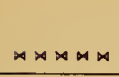 & $\triangle \triangle \triangle \triangle \triangle X$ & $\triangle M \triangle \triangle M$ & $\bowtie \bowtie \bowtie \bowtie \bowtie$ & 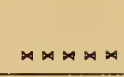 & 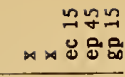 \\
\hline 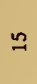 & 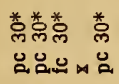 & 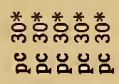 & 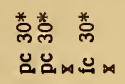 & 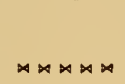 & 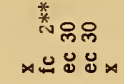 & 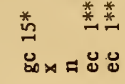 \\
\hline \pm & 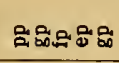 & 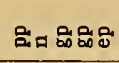 & 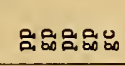 & 용요 & 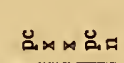 & 음 \\
\hline 9 & 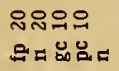 & 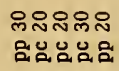 & 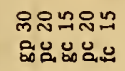 & 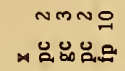 & 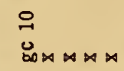 & $\begin{array}{l}\text { Dิ } \\
\text { ลีะேम }\end{array}$ \\
\hline$\approx$ & 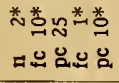 & 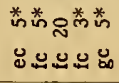 & 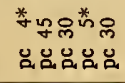 & 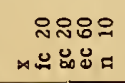 & 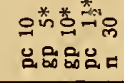 & 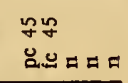 \\
\hline$=$ & 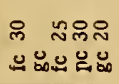 & 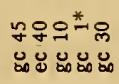 & 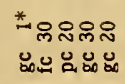 & 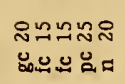 & 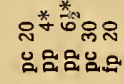 & $\begin{array}{l}\text { ర్లి } \\
\text { 며뎌 }\end{array}$ \\
\hline$\stackrel{\circ}{\circ}$ & 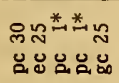 & 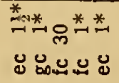 & 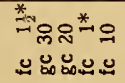 & 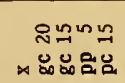 & 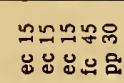 & 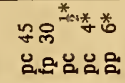 \\
\hline$a$ & 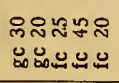 & 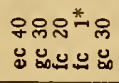 & 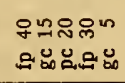 & 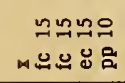 & 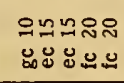 & 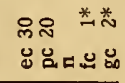 \\
\hline$\infty$ & 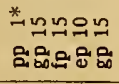 & 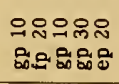 & 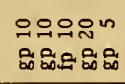 & 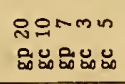 & 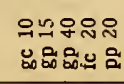 & $\begin{array}{l}\text { 옹 } \\
\text { 을ㅁㅁ }\end{array}$ \\
\hline n & 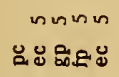 & 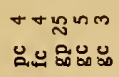 & 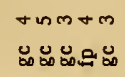 & 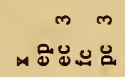 & 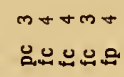 & 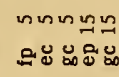 \\
\hline 0 & 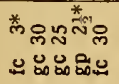 & 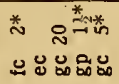 & 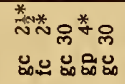 & 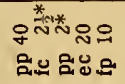 & 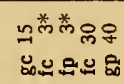 & 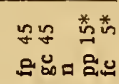 \\
\hline in & 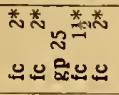 & 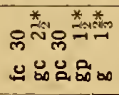 & 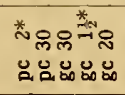 & 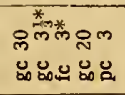 & 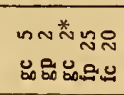 & 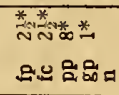 \\
\hline$\sigma$ & 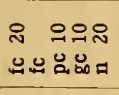 & 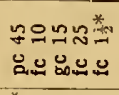 & 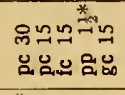 & 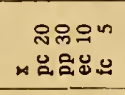 & 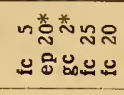 & 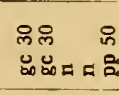 \\
\hline$m$ & 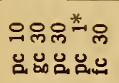 & 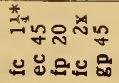 & 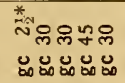 & 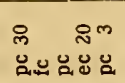 & 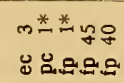 & 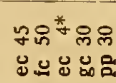 \\
\hline$\sim$ & 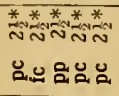 & 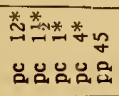 & 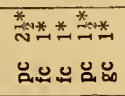 & 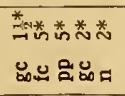 & 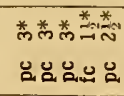 & 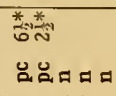 \\
\hline-1 & 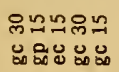 & 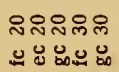 & 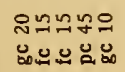 & 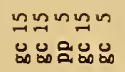 & 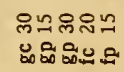 & 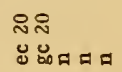 \\
\hline
\end{tabular}




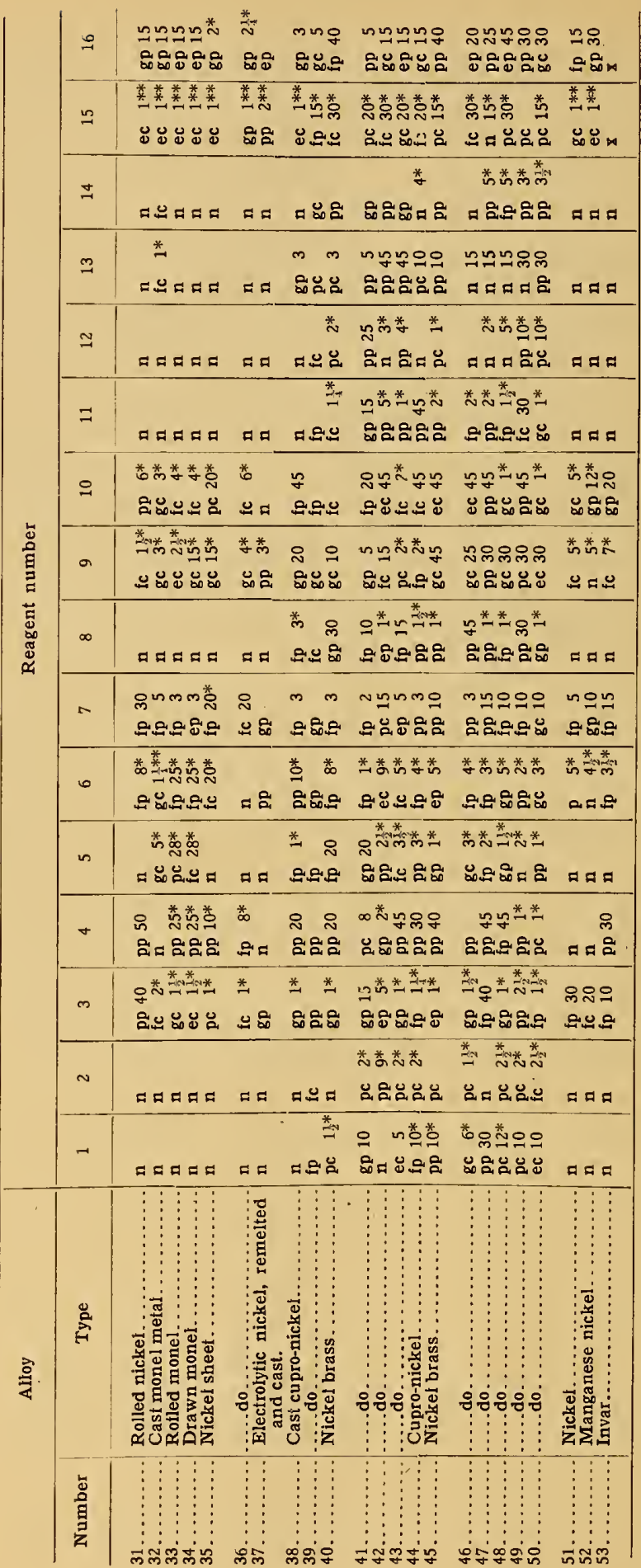




\section{NATURE OF CONTRAST ETCHING}

The terms "contrast" and "plain" etching are used to designate the character of the results obtained with different reagents upon any type of alloy and particularly those consisting of only one constituent, such as the metals, the $\alpha$ brasses and bronzes, $\beta$ brass, $\gamma$ brass, etc. Microscopic examination of such materials after plain etching usually reveals only the grain boundaries as a network of black lines, together with such extraneous features as inclosures. The grains show no "individuality" other than that of size and shape. However, in the same material after contrast etching, each grain has an individuality of its own which is the result in a large measure of its relative brightness as compared to the neighboring grains.

Such contrast may be developed in at least two very different ways. If the polished surface of the specimen is etched sufficiently, a differential roughening of the various grains will result as the crystalline facets are revealed within the boundaries of the different grains. Since the orientation of all the facets within any particular grain is the same, it follows that the light incident upon such an etched section of a crystal will be reflected in a definite manner. The direction of the reflected beam varies for different grains and depends upon the orientation of the crystalline facets. Thus, a crystal will appear dark or light according to the position of the eye of the observer with respect to the bearn reflected by this crystal.

Fig. I shows the appearance of a very deeply etched brass. The contour of the etched surface was revealed by using sections perpendicular to the etched surface, precautions being first taken to protect it by means of a coating of electrolytically deposited copper. The micrographs plainly show the regularity in the roughening of the section of a crystal and also that it conforms to the crystalline orientation of the grain as revealed by the etching pits. This means of producing contrast in etching is well understood and has been frequently described. The second method, which is given below, is not so well known.

It is often desirable in the study of the microstructure of metals to produce contrast without much roughening of the surface. This may be accomplished by the use of reagents which cause the formation of a very thin film on the surface, the thickness of which varies from grain to grain. This effect has deen described in considerable detail for copper $^{3}$ and is usually attributed to 
oxidation films. The part that such films play in contrast etching may be demonstrated rather strikingly, as is shown in Figs. 2,3 , and 4 , by a double etching process.

Hydrogen sulphide was used as a convenient means for producing a thin film on the specimen, and an aqueous solution of silver nitrate was used as the reagent for etching, which of itself produces little, if any, contrast (Fig. 2a). When the slightly warmed polished brass specimen (No. I I, Table I) was suspended in a bottle of hydrogen sulphide gas, to which a drop of concentrated hydrochloric acid had been added to accelerate the at. tack, a film having the appearance shown in Fig. $2 b$ was produced. No evidence of crystalline structure was revealed. On

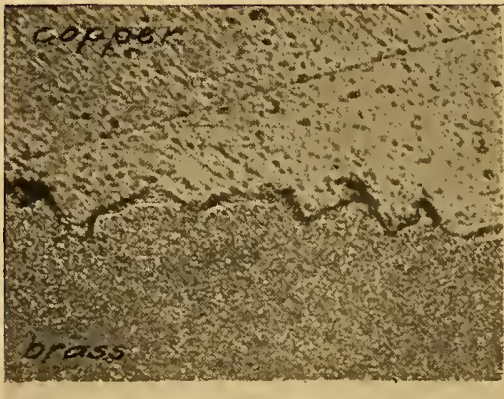

a

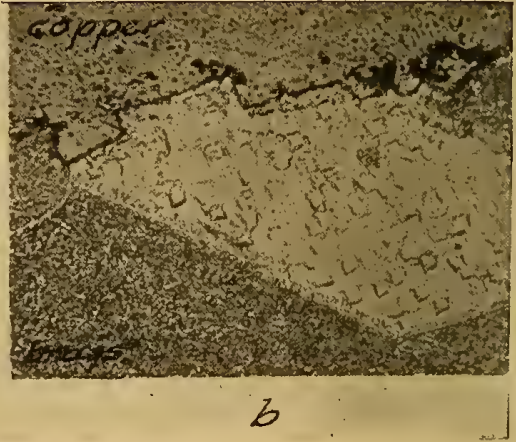

FIG. I.-Roughening of the surface of crystals of brass as a result of prolonged etchings of a polished surface. $\times 500$

A polished section of at $a$ brass (alloy 10, Table I) was etched $\mathrm{I}_{2}$ hours in 50 per cent copper ammonium chloride and a section perpendicular to the etched lace was then examined after etching with copper ammonium chloride. Note the similarity in orientation of the notches in the etched surface of $(a)$, which represents a portion entirely within a single crystal. Note in $(b)$ how the orrentation of the notches of the etched surface is the same as that of the etching pits within the crystal.

the other hand, when a specimen etched by the means of silvernitrate solution was suspended in the hydrogen sulphide the sulphide film formed on certain crystals with greater readiness

IEXPLANATION OF FIG, 2, PAGE 645

(a) $\alpha$ brass (alloy Ir, Table I) etched with to per cent solution of silver nitrate. Note the absence of contrast.

(b) Same specimen as (a), which after polishing was suspended in an atmosphere of hydrogen sulphide lor I minute. Note the surface film of sulphide. The black spots mark the location of the inclusions of lead in the alloy.

(c) The specimen (a!loy $\mathrm{YI}$ ) after being etched as in (a) was placed in hydrogen sulphide as in (b). The contrast of the etch pattern produced was much less pronounced than in $(d)$.

(d) The specimen (alloy Ir) after being filmed by means of hydrogen sulphide as in (b) was etched with silver nitrate solution as in $(a)$. Note the brilliant contrast which r esulted .

(e) $\alpha \beta$ brass (alloy ${ }_{14}$, Table $\mathrm{I}$ ) etched with ro per cent silver nitrate solution.

$(f)$ Same specimen as $(e)$ which arter polishing was placed in an atmosphere of hydrogen sulphide.

$(g)$ Same specimen as $(e)$, etched with silver nitrate solntion and then filmed with sulphide as in $(f)$.

$(h)$ Same specimen as $(e)$, filmed with hydrogen sulphide asin $(f)$, then etched with silver nitrate as

in $(e)$. Note the definite contrasted etch pattern. 


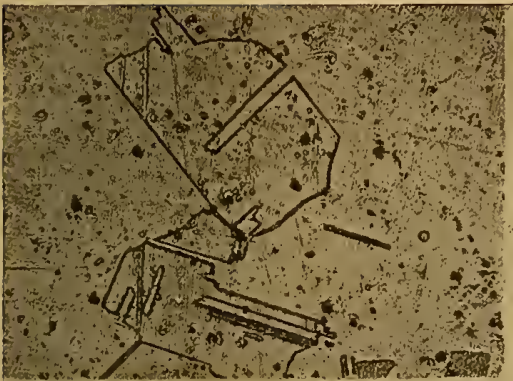

a

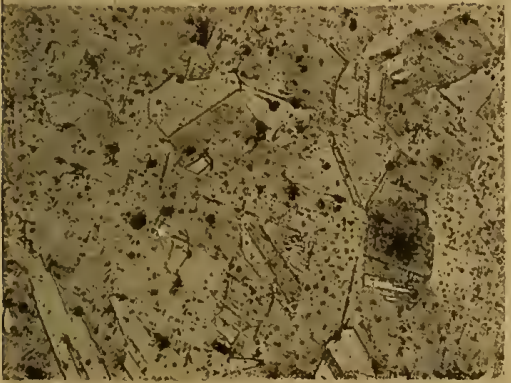

c

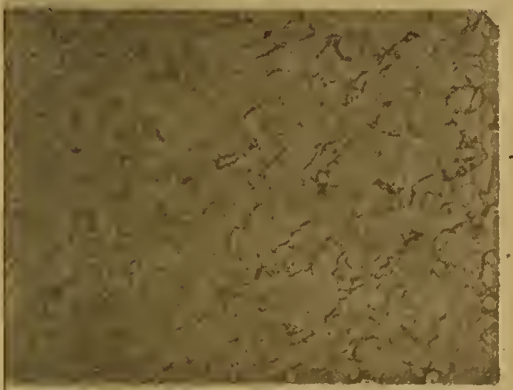

e

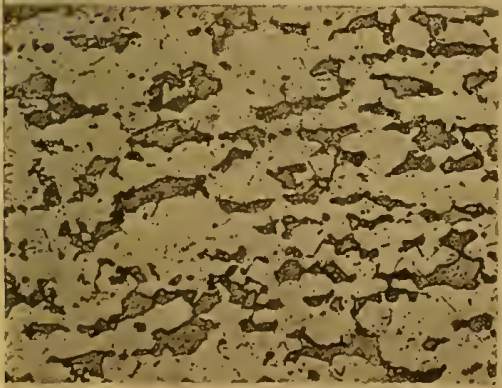

9

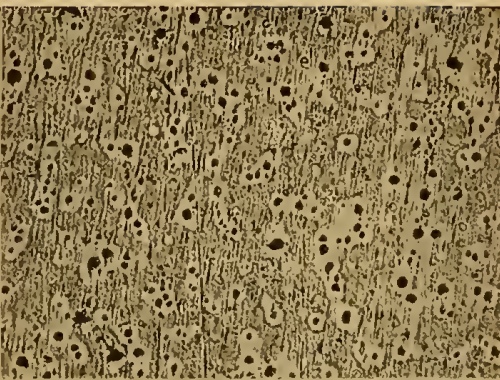
b

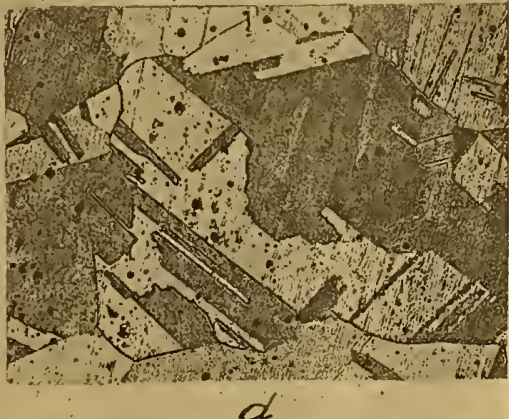

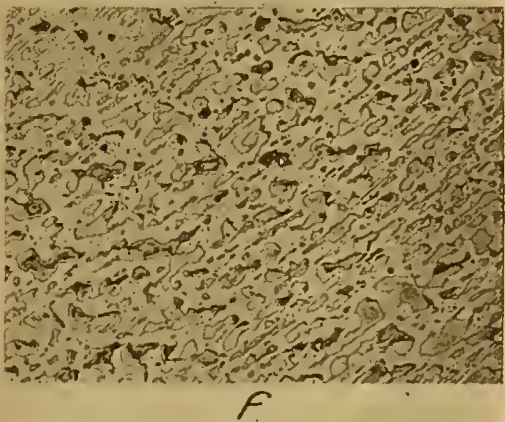

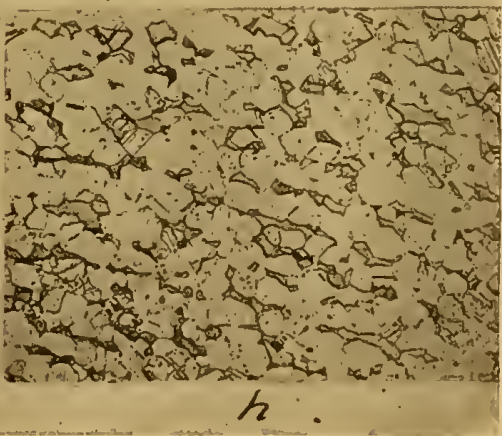

FIG. 2,-Microstructure of brass etched with hydrogen sulphide, illustrating importance of a surface film in producing contrast between crystals of etched surface, $\quad \times 100$ [For further cxplanation of Fig. 2, sce p. 644] 
than on others, so that a slightly contrasted etch pattern resulted. However, by far the best results were obtained by first producing a uniform sulphide film on the surface of the polished specimen and then etching the filmed sample in the silver-nitrate solution (Fig. $2 d$ ). Such a procedure gave excellent results with all the $\alpha$ and the $\alpha \beta$ brasses. With cast zinc bronze the best results were obtained by producing the sulphide film upon the etched surface rather than etching the previously filmed surface (Fig. 3).

The fact that the results given above are of rather general application and do not depend upon any peculiar properties of the sulphide film was demonstrated by using oxide films instead of sulphide. The specimens were gently heated in the air until a uniform thin coating of oxide had formed and were then etched with silver-nitrate solution. Fig. 4 shows the results obtained with some of the specimens. For demonstration purposes, one is somewhat restricted in the choice of reagents, since it is necessary that the solution used be one that produces a "plain" etch pattern. For practical use, of course, this limitation does not hold.

\section{ETCHING CHARACTERISTICS OF COPPER ALLOYS}

\section{BRASS}

(a) $\alpha$ BRAss.-There is nothing strikingly different in the etching characteristics of the $\alpha$ brasses from those of copper. Figs. 5 and 6 show the general effect of the different reagents upon two of the alloys used. The results shown are quite representative of the behavior of the other $\alpha$ brasses of a different copper-zinc ratio toward the same reagents. The data summarized in Table 3 show this in a general way. Although some differences were observed in the etching period for $\alpha$ brasses differing in their zinc content, they were not pronounced and systematic enough to permit any generalization being made. From the results obtained it appears that the addition of tin to an $\alpha$ brass in amounts of approximately I per cent renders the etching of the specimen more difficult than that of a similar brass containing no tin. Not only was the etching period lengthened, but the general appearance of the etched surface was not nearly so satisfactory as that of a similar alloy containing no tin. Fig. 7 illustrates this. The presence of particles of lead in an $\alpha$ brass did not seriously affect its etching characteristics, although with a very few reagents, as shown in Fig. 8 and Fig. $2 b$, an unetched 

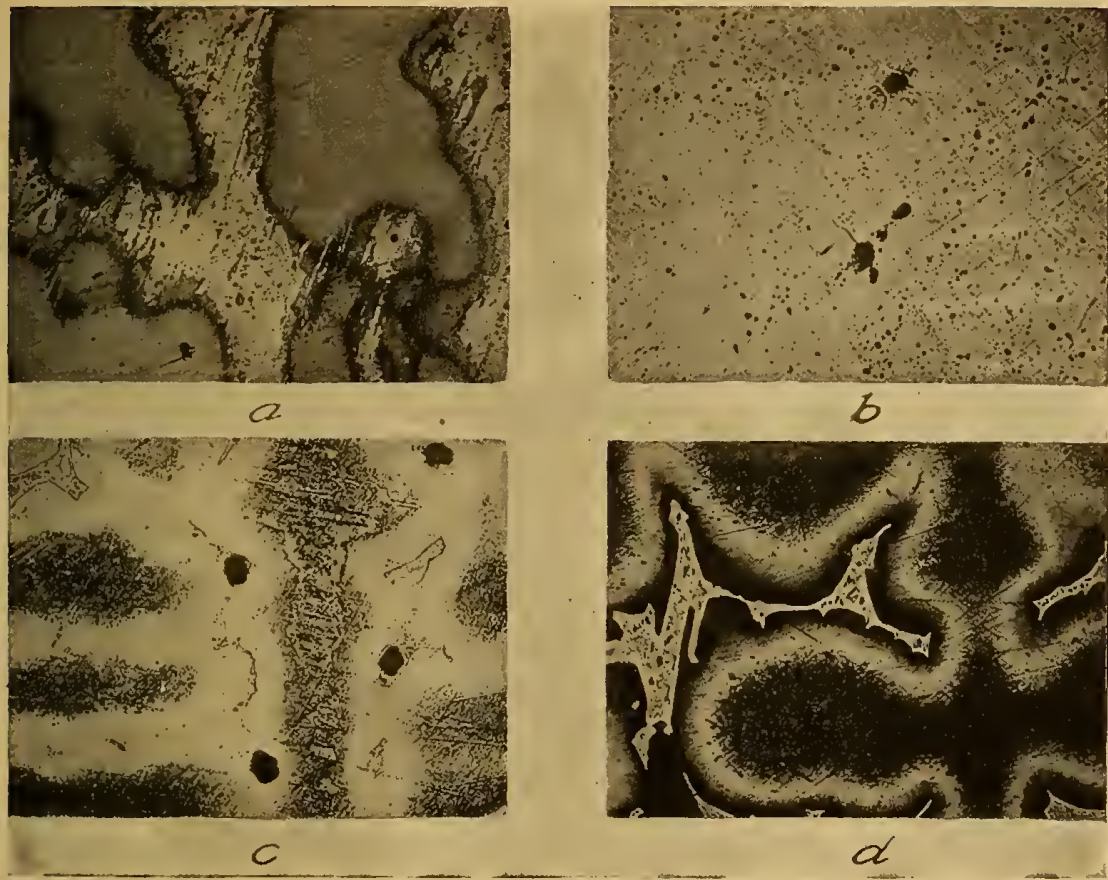

Fig. 3.-Microstructure of cast bronze illustrating the importance of surface films in producing contrast upon etching. $\times 100$

(a) Cast zinc bronze (alloy 24, Table I) etched with to per cent solution of silver nitrate. Note the adhering silver covering the eutectoid constituent.

(b) Specimen (a) which, after polishing, was placed in an atmosphere of hydrogen sulphide for I minute.

(c) Specimen (a) filmed by hydrogen sulphide as in $(b)$, then etched with silver nitrate as in (a).

$(d)$ Specimen $(a)$ etched with silver nitrate and then exposed in hydrogen sulphide as in $(b)$. Note the brilliant contrast produced. The adhering silver covering the autectoid-see $(a)$-protects this constituent from the action of the sulphide and thus increase the contrast.

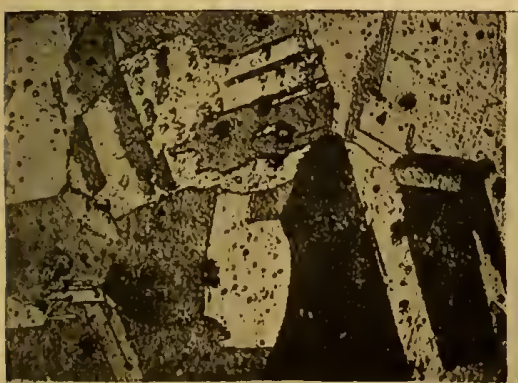

a

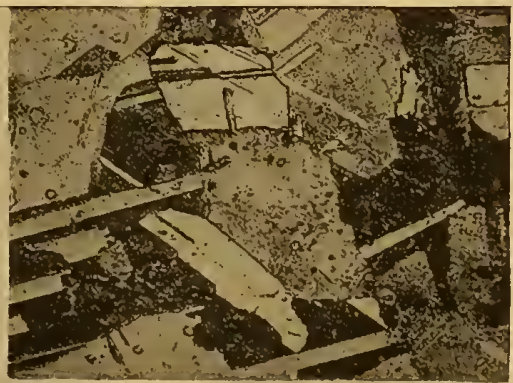

$b$

FIG. 4.-Microstructure of annealed $\alpha$ brass illustrating the importance of a surface film produced by oxidation in producing contrast. $\times 100$

The polished specimens were heated for ro minutes on a hot plate in the air, so as to produce a uniform oxide film. The oxidized specimens were then etched with to per cent silver nitrate solution.

(a) Alloy Ir, Table 1. See Fig. 2 (a).

(b) Alloy 6, Table I. 

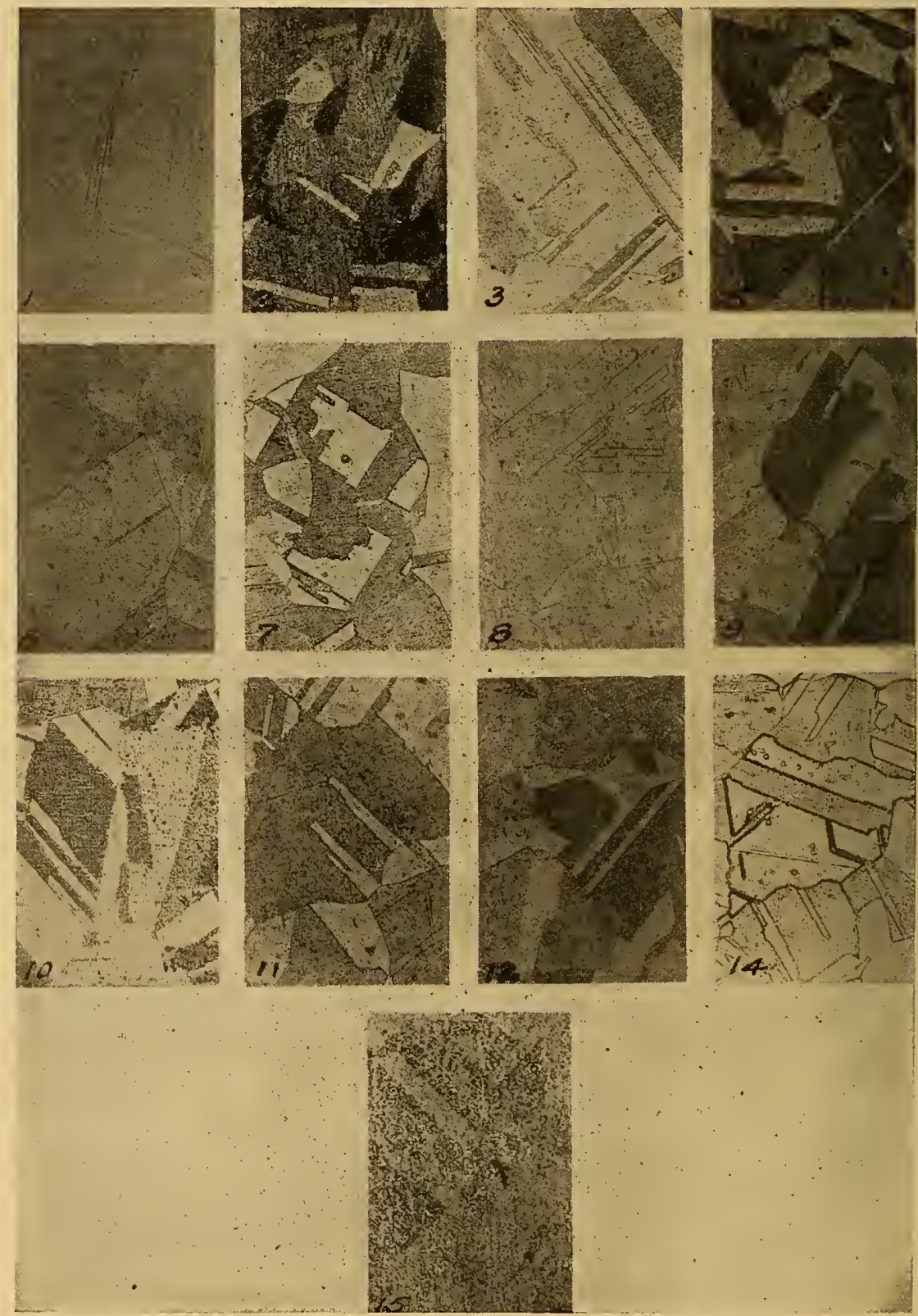

FIG. 5.-Microstructure of annealed $\alpha$ brass sheet of high copper content (alloy 2, Table I) illustrating the etching characteristics of the material. $\times 100$

The numbers indicate the etching reagent used. See Table 2. 

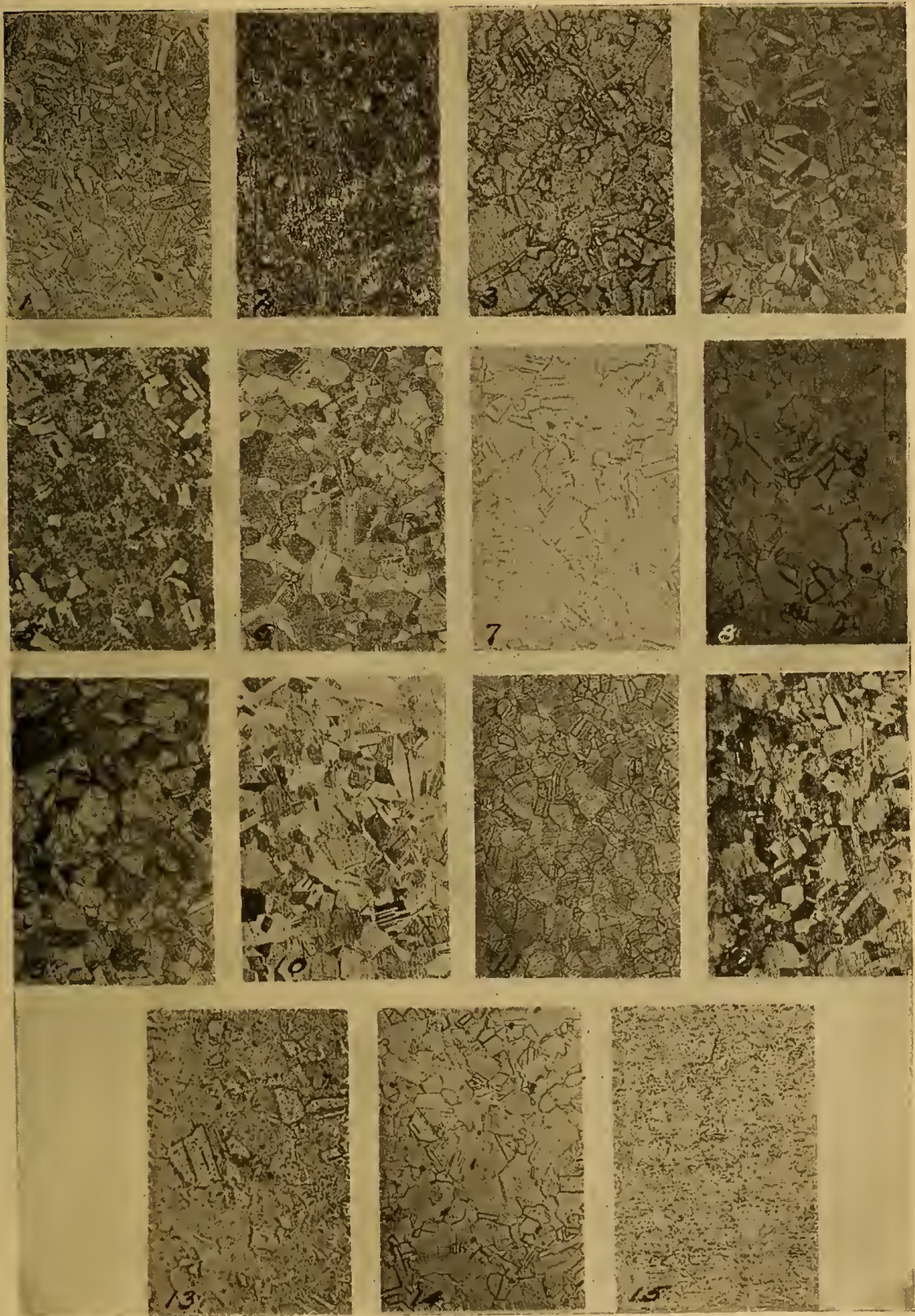

FIG. 6.-Microstructure of annealed $\alpha$ brass sheet of low copper content (alloy 8, Table I) illustrating the etching characteristics of the material. $\times 100$

The numbers indicate the etching reagent used, see Table 2. Compare with Figs. 7 and 8. $88775^{\circ}-22-3$ 

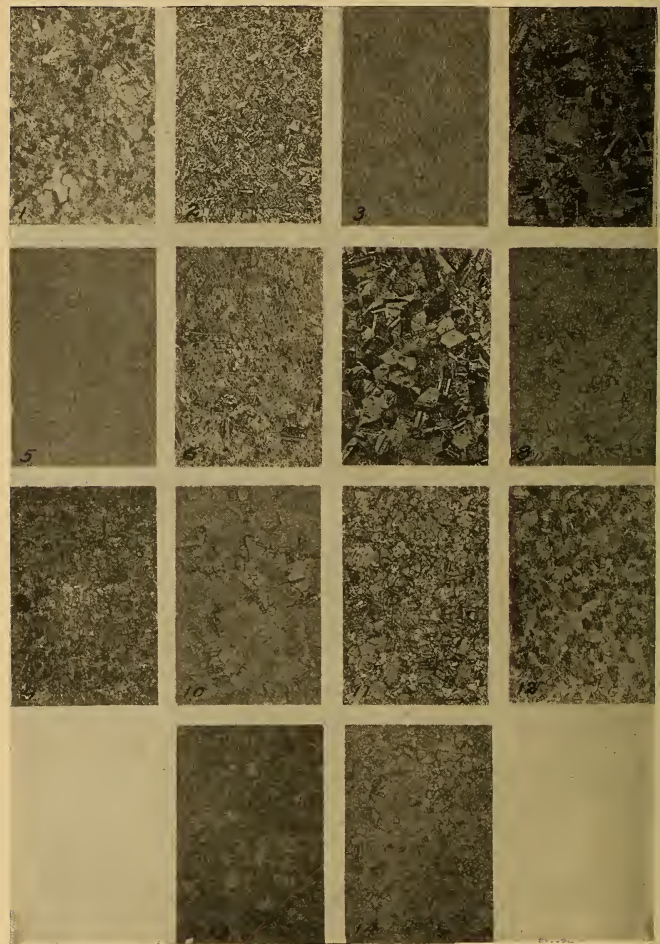

Fig. 7.-Microstructure of annealed $\alpha$ brass sheet of low copper content containing tin (alloy 9, Table $I$ ) illustrating the etching characteristics of the alloy. $\times 100$

The number on each micrograph indicates the etching reagent used (Table 2). Compare with Figs: 6 and 8. 

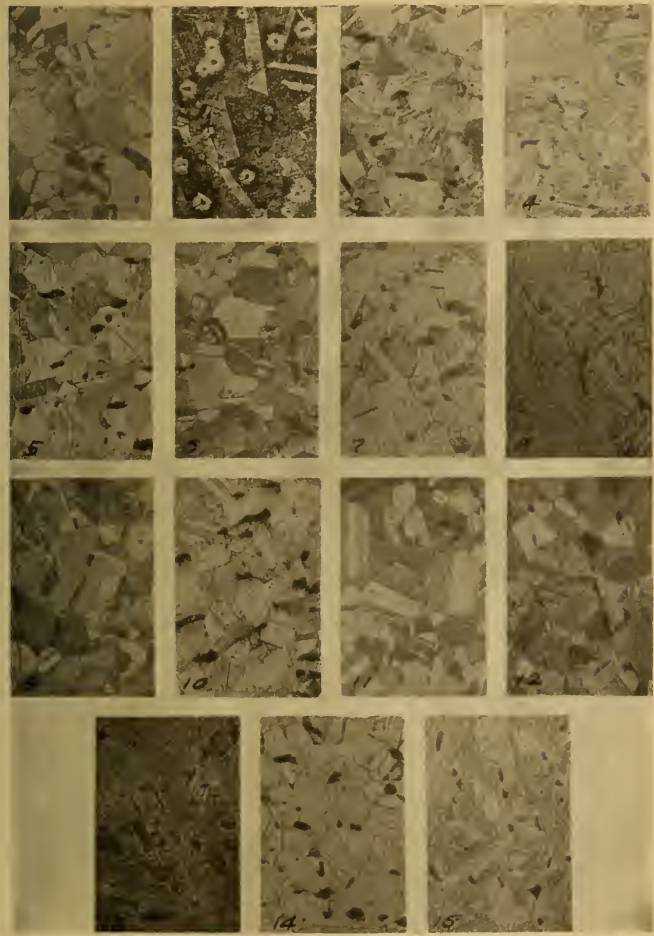

FIG. 8. - Microstructure of annealed $\alpha$ brass sheet of low copper content containing lead

(alloy 7, Table 1 ) illustrating the etching characteristics of the alloy. $\times 100$

The uumber on each micrograph indicates the etching reagent used (Table a). Compare with Figs. 6 and 7. 

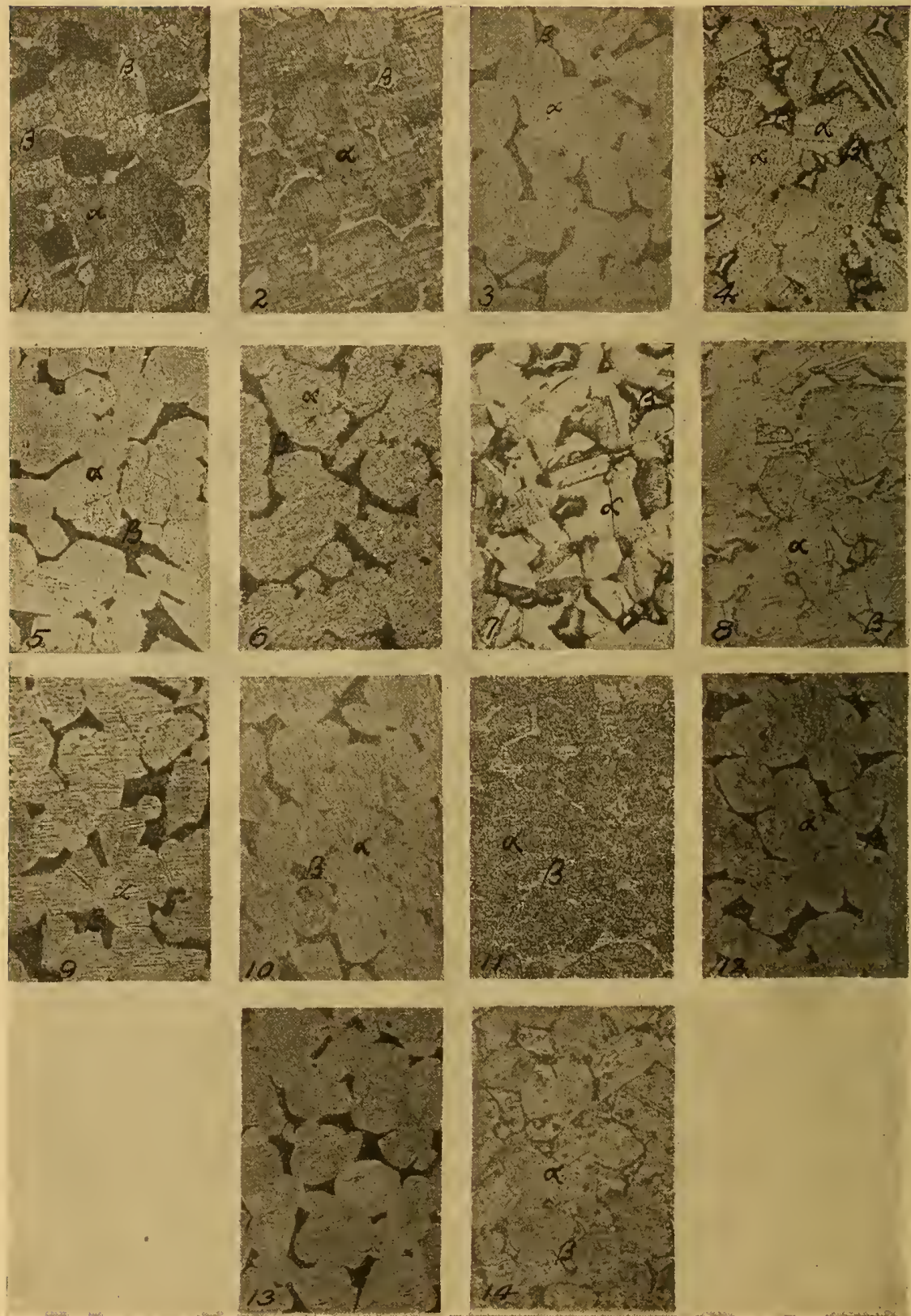

FIG. 9. - Microstructure of annealed $\alpha \beta$ brass sheet (alloy I3, Table I) illustrating the etching characteristics of this alloy. $\times$ IOO.

The number on each micrograph indicates the etching reagent used (Table 2). 
"halo" surrounded each isolated globule of lead. However, this effect was not pronounced or general enough to be considered of much significance.

(b) $\alpha \beta$ BRASS.-The introduction of a second metallographic constituent modifies very considerably the etching properties of brass. Fig. 9 shows the microscopic appearance of an $\alpha \beta$ brass (specimen I3, Table I) after being etched with the various types of reagents. The results shown may be considered as typical for brasses of this type. The relative amounts of the two constituents vary in different alloys according to the copper-zinc ratio and the form and arrangement of the two constituents according to the treatment of the alloy.

As will be noted in Fig. 9, the relative intensity of the attack of the two constituents varied with different solutions. By reagents which have a strong solvent action, such as nitric acid or sulphuric acid containing potassium dichromate, the $\beta$ constituent was found to be readily attacked, so that, on account of the difference in level which resulted, this constituent appeared dark and the $\alpha$ matrix, in which the grain boundaries had been developed, light. Other reagents which were of a milder nature were found to color the $\beta$ grains so that they appeared dark in the light structureless $\alpha$ matrix. With a few reagents for the same specimen this effect was reversed so that the $\beta$ constituent appeared as uncolored areas in a slightly darkened background of the $\alpha$ matrix. In other cases each of the constituents remained uncolored and only the grain boundaries were revealed. Of course in such a case the two could be readily distinguished from each other upon visual examination by their difference in color. A further complication was sometimes noted in the case of alloys in which the $\alpha$ constituent was in considerable excess. The grains constituting the $\alpha$ matrix were found to etch in the manner previously described, so that considerable contrast between the different $\alpha$ grains resulted. This rendered the $\beta$ constituent relatively inconspicuous, particularly so in the micrograph.

The fact that the difference in the behavior of the $\beta$ constituent is not entirely dependent upon the nature of the etching reagent employed is illustrated by the results shown in Fig. Io. The alloy used was of the following composition: Copper, 60.06 per cent; tin, $0.5^{8}$ per cent, nickel, manganese, and phosphorus, not detected; zinc, by difference, 39.26 per cent, and had been rolled into a "round" of $3 \frac{1}{2}$ inches diameter. In numerous streaks in $88775^{\circ}-22-4$ 
the central portion the $\beta$ constituent was etched dark, while in adjacent portions this constituent appeared light-colored. Apparently these streaks corresponded to the large crystals of the ingot and had suffered no change other than that of shape by the rolling of the material. The difference in the etching properties of the $\beta$ constituent were shown best by such reagents as ammonium copper chloride, ferric chloride, sulphuric acid containing an oxidizer such as potassium dichromate or potassium permanganate. With some other reagents, for example, silver nitrate and chromic acid, the $\beta$ constituent was etched uniformly

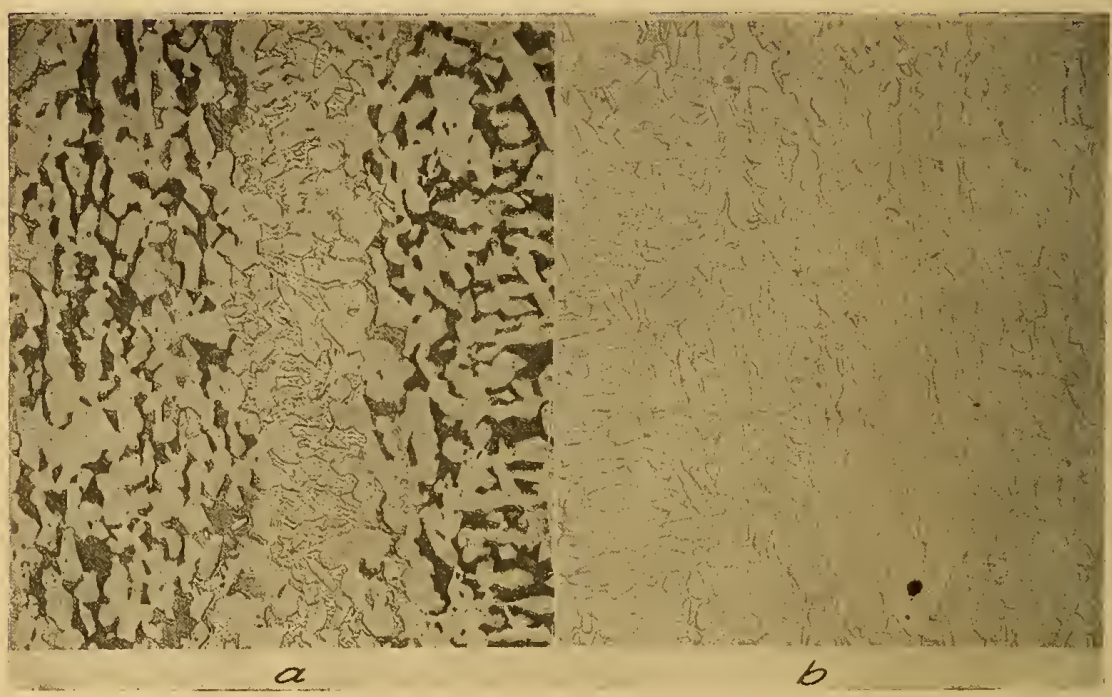

FIG. I0.-Microstructure of $\alpha \beta$ brass etched with different reagnets illustrating the anomalous behavior of the $\beta$ constituent. $\times 100$

(a) Etching reagent, copper ammonium chloride solution (No. Ir, Table 2). Note the darkened appearance of the $\beta$ constituent in certain streaks; in other portions this constituent remained uncolored. This difference in etching properties was characteristic and persisted after the specimen was annealed.

(b) Same specimen as (a); etching reagent, chromic acid solution (No. 8, Table 2 ). Note uniform appearance of the two constituents across the entire surface.

in all of the crystals. This difference in the etching properties of the $\beta$ constituent was found to persist after the material had been annealed. Heating the specimen for four hours at approximately $45^{\circ} \mathrm{C}$ did not materially affect the etching properties of the alloy. It may be concluded, then, that the anomalous behavior of the $\beta$ constituent in different crystals can not be attributed to internal stresses which might exist within the wrought material. There is some evidence, however, which suggests that the direction in which the crystal was sectioned has a bearing upon the relative etching properties of the two constituents 
(c) High Zinc AlLoys.-Of the copper-zinc alloys of relatively high zinc content only the $\beta$ alloy is of any considerable industrial importance. However, in order to demonstrate their relative etching characteristics, alloys representative of each of the different structural types were prepared and examined. In etching $\beta$ brass the same question arises, as to a plain or a contrast effect as with the $\alpha$ alloys. Fig. II shows the results obtained with this alloy when etched with several different types or reageants.

Figs. I 2 and I 3 are given to illustrate the characteristics of two of the high zinc alloys of duplex structure, the $\beta \gamma$ and $\epsilon \eta$, the latter
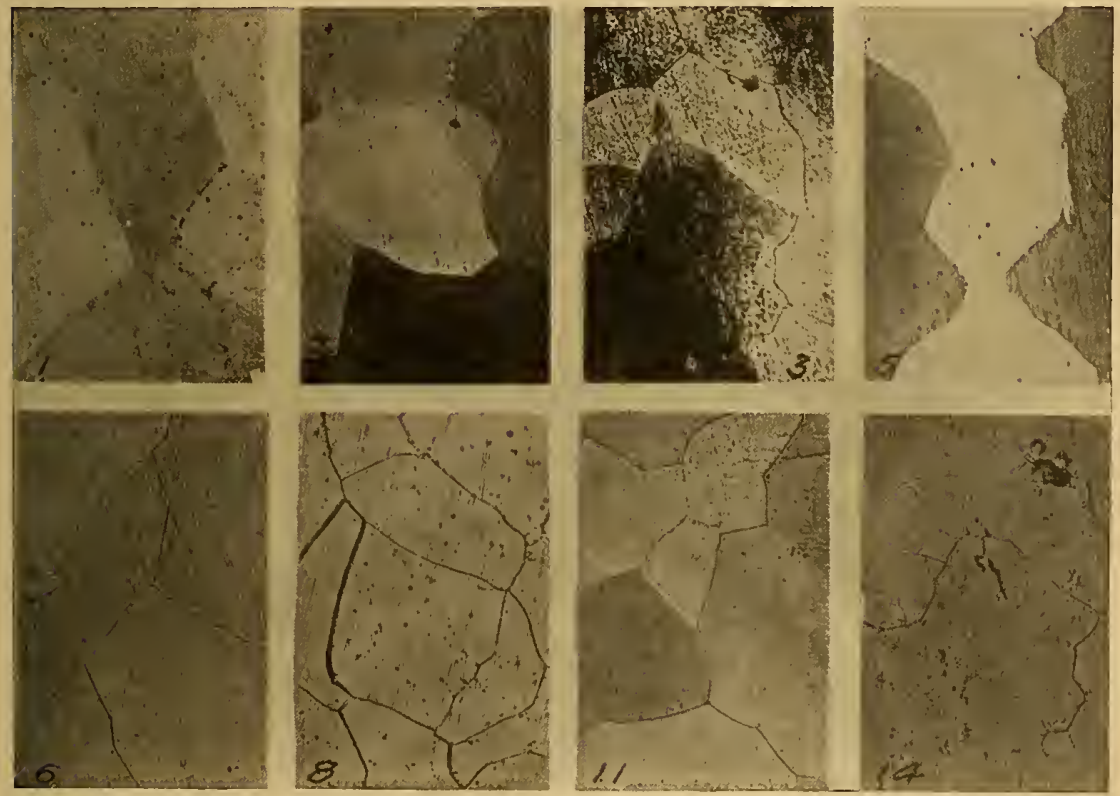

FIG. II.-Microstructure of cast $\beta$ brass (alloy I6, Table I) illustrating the etching characteristics of the alloy. $\times 100$

The number on each micrograph indicates the etching reagent used (Table 2 ).

one being one of very high zinc content. It will be noted that, although as a rule the zinc-rich constituent was the one which was darkened, with several reagents a reversal in the etching effect of the two constituents occurred. As might be expected, the alloys of high zinc content resemble zinc in their properties more than copper and were readily etched by some reagents-for example, ammonium chloride-which had no effect upon the alloys of high copper content. The use of oxygen or strong oxidizers in the etching reagents was not so necessary for the high zinc alloys as for those of high copper content. 

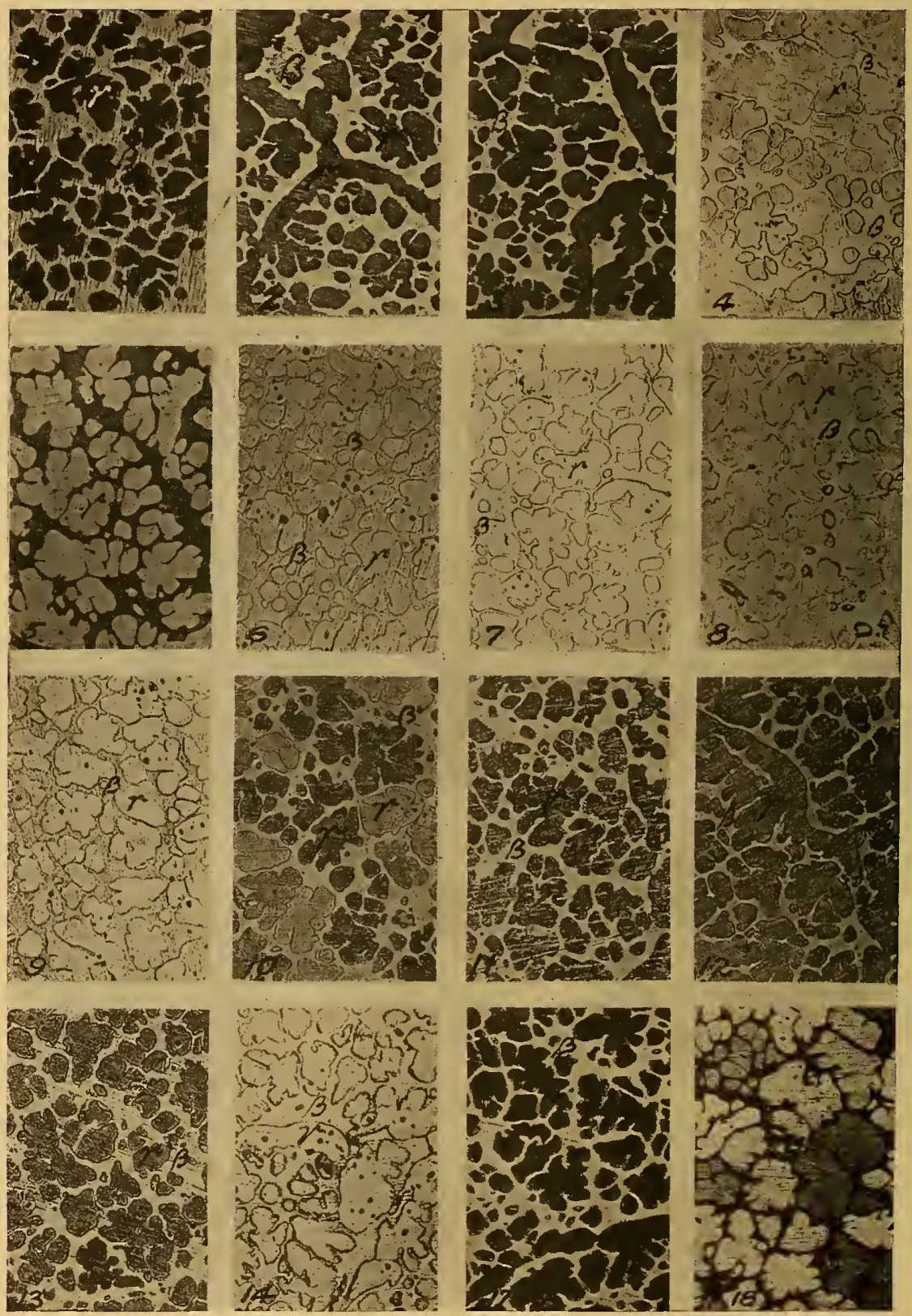

FIG. I2.-Microstructure of cast copper-zinc alloy containing the $\beta$ and $\gamma$ constituents (alloy 17 , Table I) illustrating the etching characteristics of the alloy. $\times$ Ioo

'The number on each micrograph indicates the etching reagent nsed (Table 2 ). In the unetched state the $\gamma$ nodules appear gray in a yellow matrix of the $\beta$ constituent. 

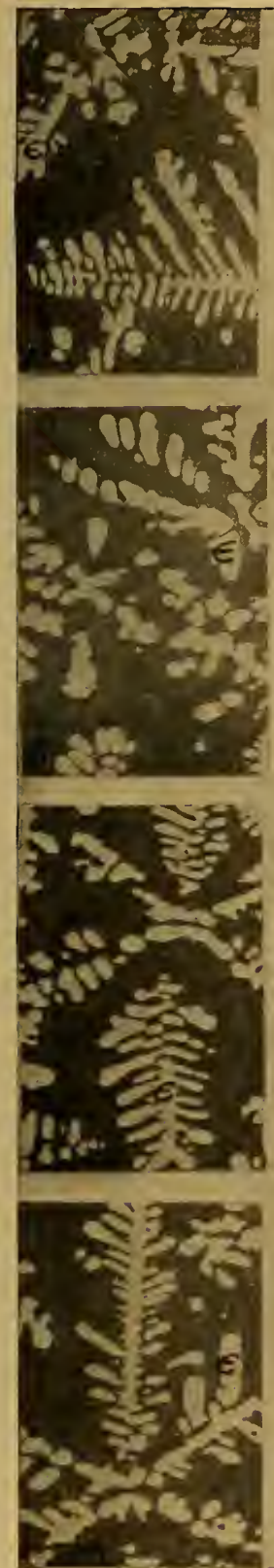
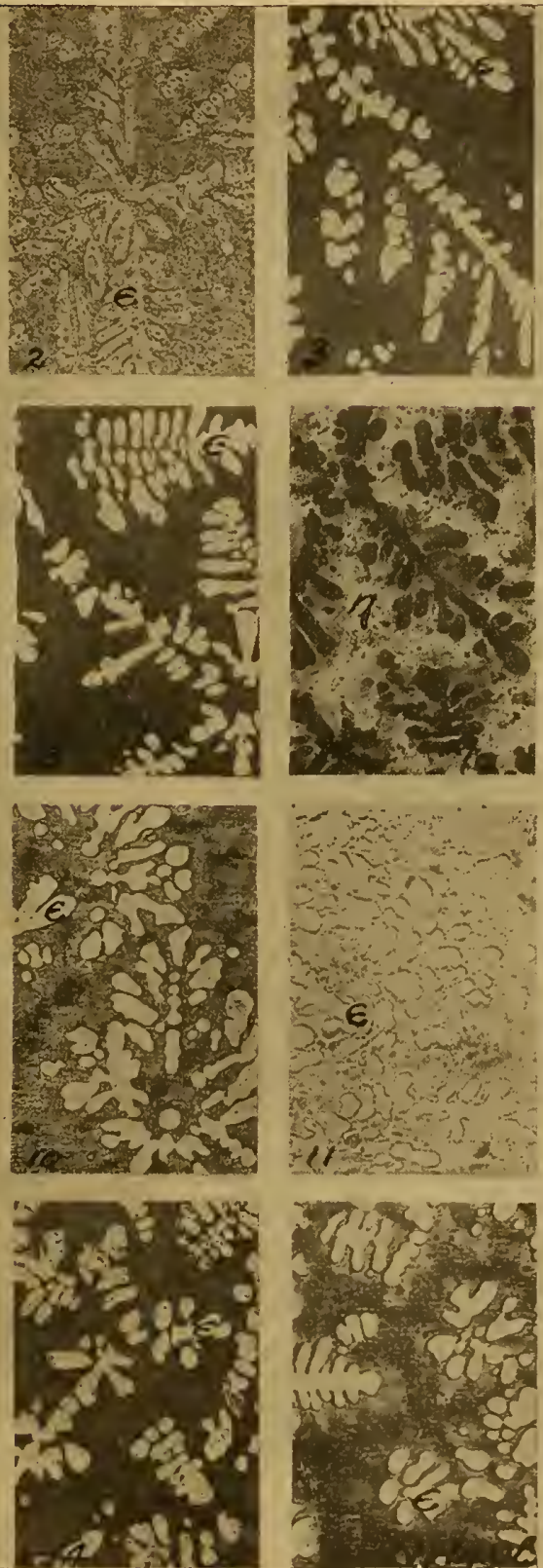
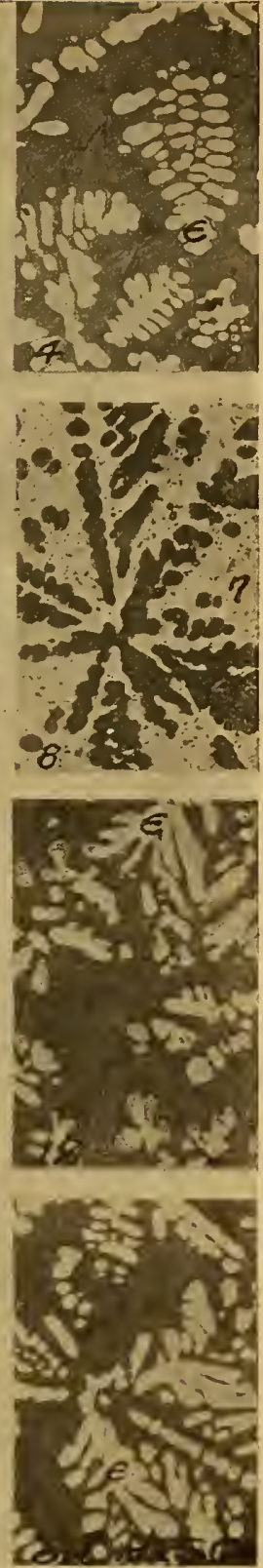

Fig. 13.-Microstructure of cast copper-zinc alloy containing the $\epsilon$ and $\eta$ constituents (alloy 2I, Table I) illustrating the etching characteristics of the matcrial. $\times 100$

The number on each micrograph indicates the etching reagent (Table 2 ) used. 


\section{BRONZE}

The $\alpha$ bronzes presented no difficulties in etching other than those already discussed for the corresponding brasses, and, in general, the results were very similar. Fig. 14 shows the results for the different types of etching reagents and illustrates which reagents are suitable for producing either a contrast or a plain etching.

The cast bronze shown in Fig. I 5 has a more complex structure, so that the variations in its behavior with different types of etching reagents were much more pronounced. The micrographs illustrate this much more forcibly than can be done in words. Incidentally they also show the care which should be used in the choice of an etching reagent according to the features of the structure of an alloy which it is desired to emphasize.

\section{ALUMINUM BRONZE}

Of all the copper alloys used, aluminum bronze (specimen 25, Table I) was found to be the most unsatisfactory in its behavior toward the various types of etching reagents used. This was true particularly for the metal in the rolled condition; when cast the alloy was etched very satisfactorily with no difficulty. Figs. I6 and $\mathrm{I} 7$ show the results obtained for the material in the rolled state and for the same alloy in the cast condition. The best results by far were obtained by passing oxygen through the etching reagent. By this means the boundaries of the crystals of the rolled material were clearly outlined and considerable contrast of the different crystals was developed. When etched with the other reagents, these features were lacking (Fig. I6).

\section{ETCHING CHARACTERISTICS OF NICKEL AND OF ALPHA NICKEL ALLOYS}

\section{NICKEL}

This metal is very much more resistant to etching than is copper or the alloys of copper just discussed. Not only are there fewer reagents that can be used for etching purposes, but also the results obtained are often far from satisfactory. Since nickel is so resistant in its chemical properties a very active reagent-for example, nitric acid-must be employed, and consequently pitting of the surface very often results. Each slight inclusion acts as a center from which the surrounding metal is dissolved, and the pits which form are often the most conspicuous of the microstructural features. There is usually a lack of contrast between the different crystals after etching, the etch pattern being of the "plain" type. 

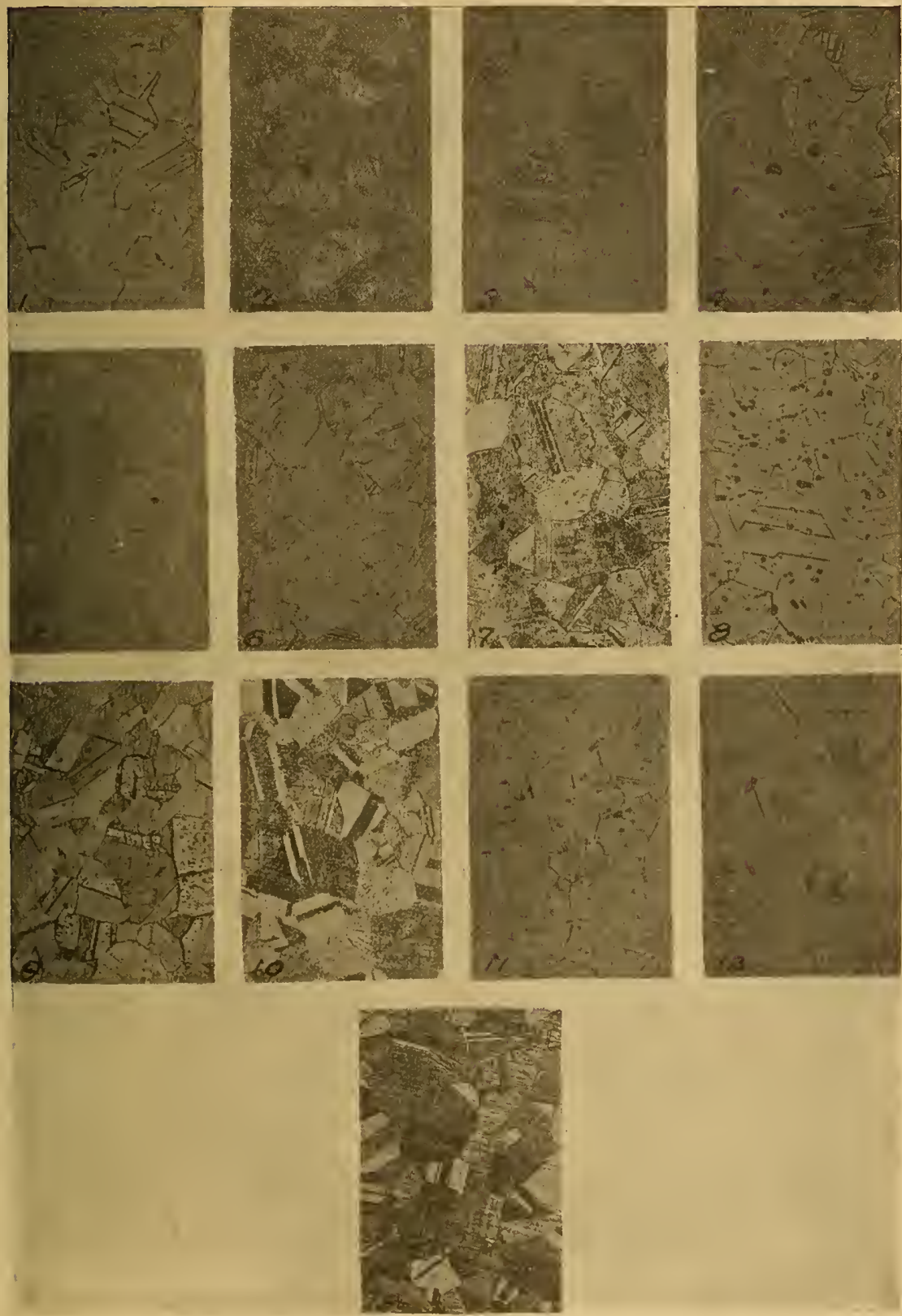

Fig. 14.-Microstructure of annealed $\alpha$ bronze sheet (alloy 23, Table I) illustrating the etching characteristics of this alloy. $\times$ IOO

The number on each micrograph indicates the etching reagent ('Table 2) used. 

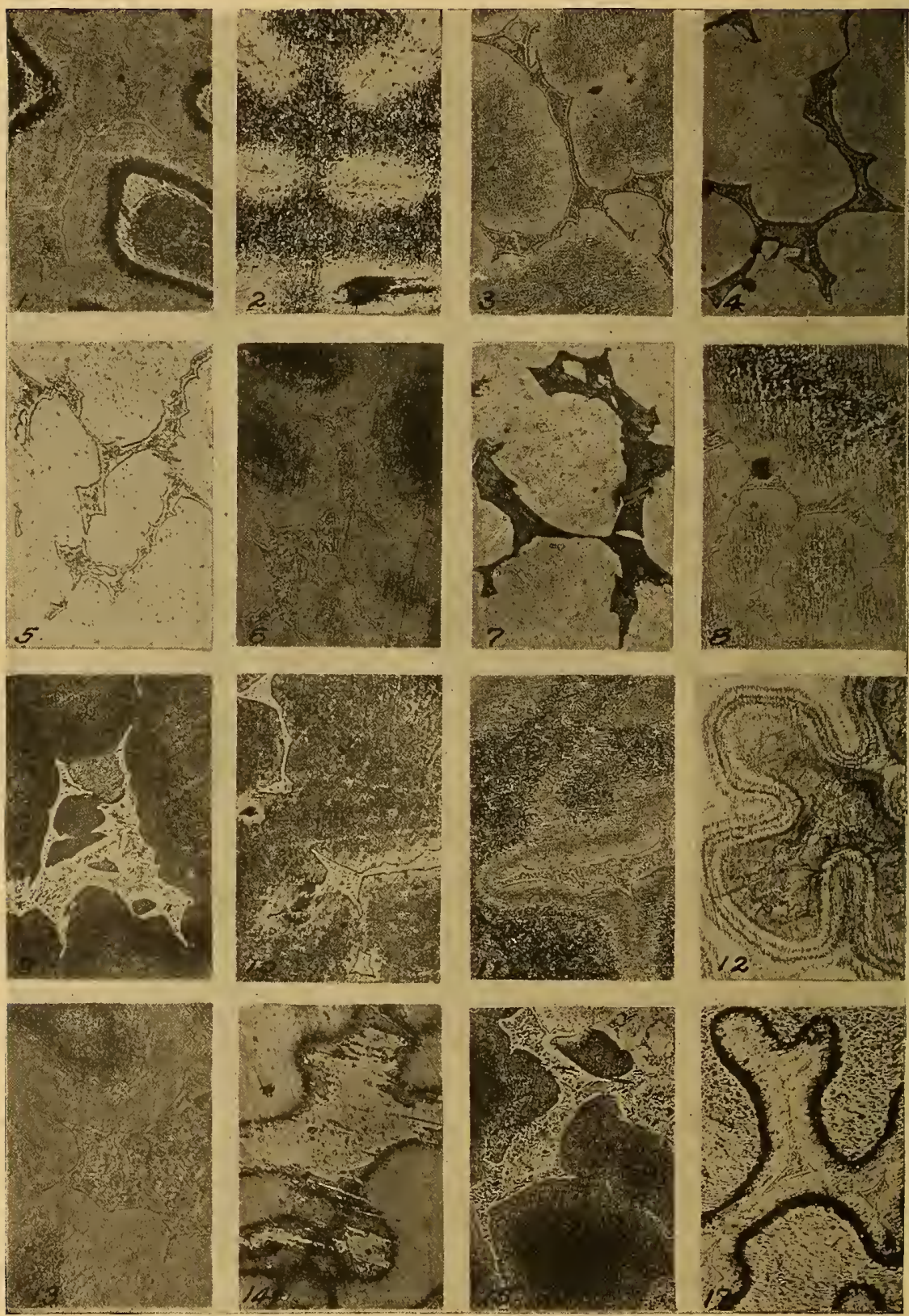

FIG. 15.-Microstructure of cast zinc-bronze containing the $\alpha$ and $\delta$ constituents (alloy 24, Table I) illustrating the etching characteristics of the alloy. $\times$ IOO

The number on each micrograph indicates the etching reagent used (Table 2). 

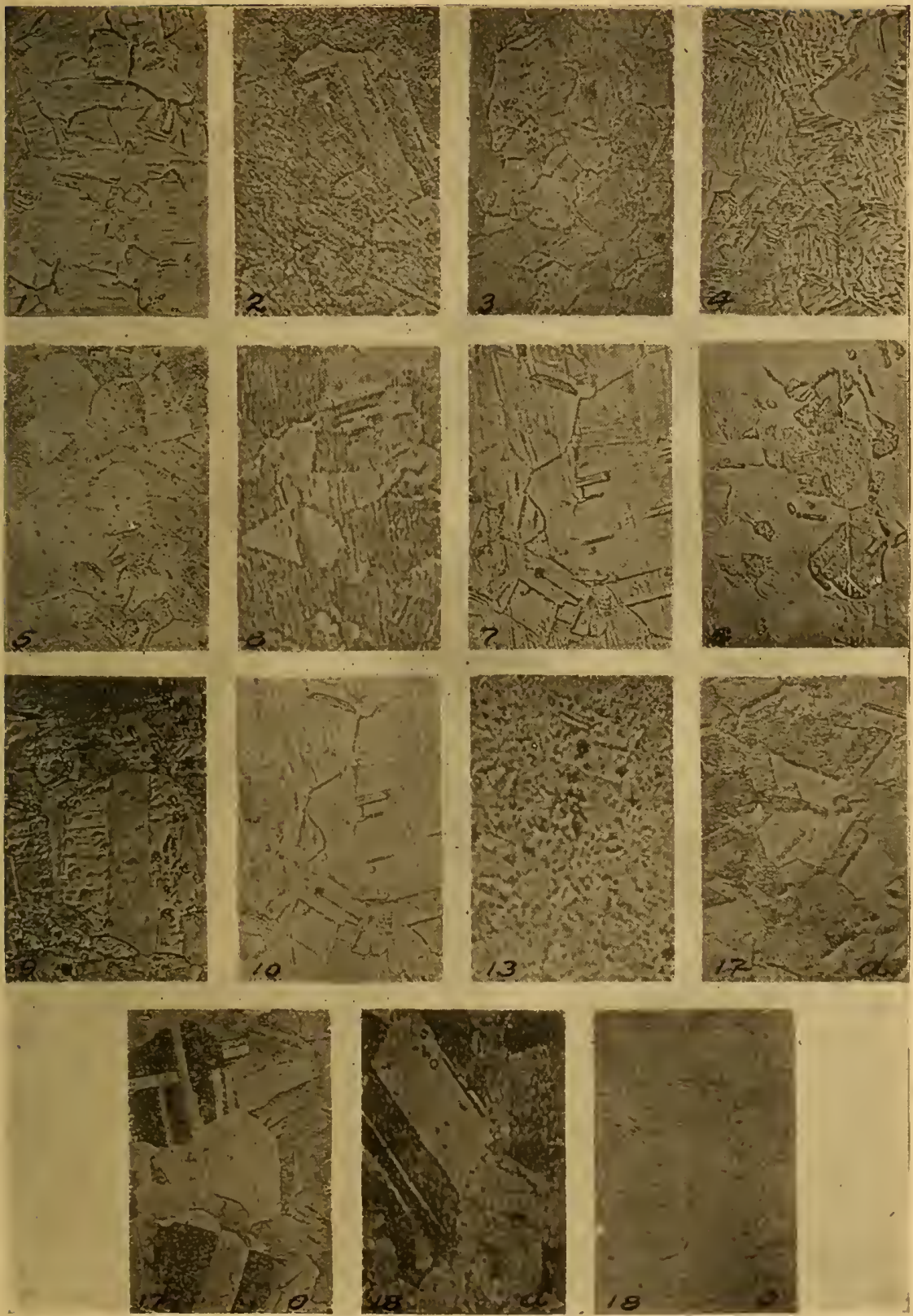

FIG. 16.-Microstructure of anncaled aluminum bronze sheet (alloy 25, Table I) illustrating the etching characteristics of the alloy. $\times 100$

The number on each micrograph indicates the etching reagent used (Table 2 ). In micrographs ${ }_{7} 7$ and $18, d$ indicates "directly in current of oxygen," $a$ "outside oxygen current." 

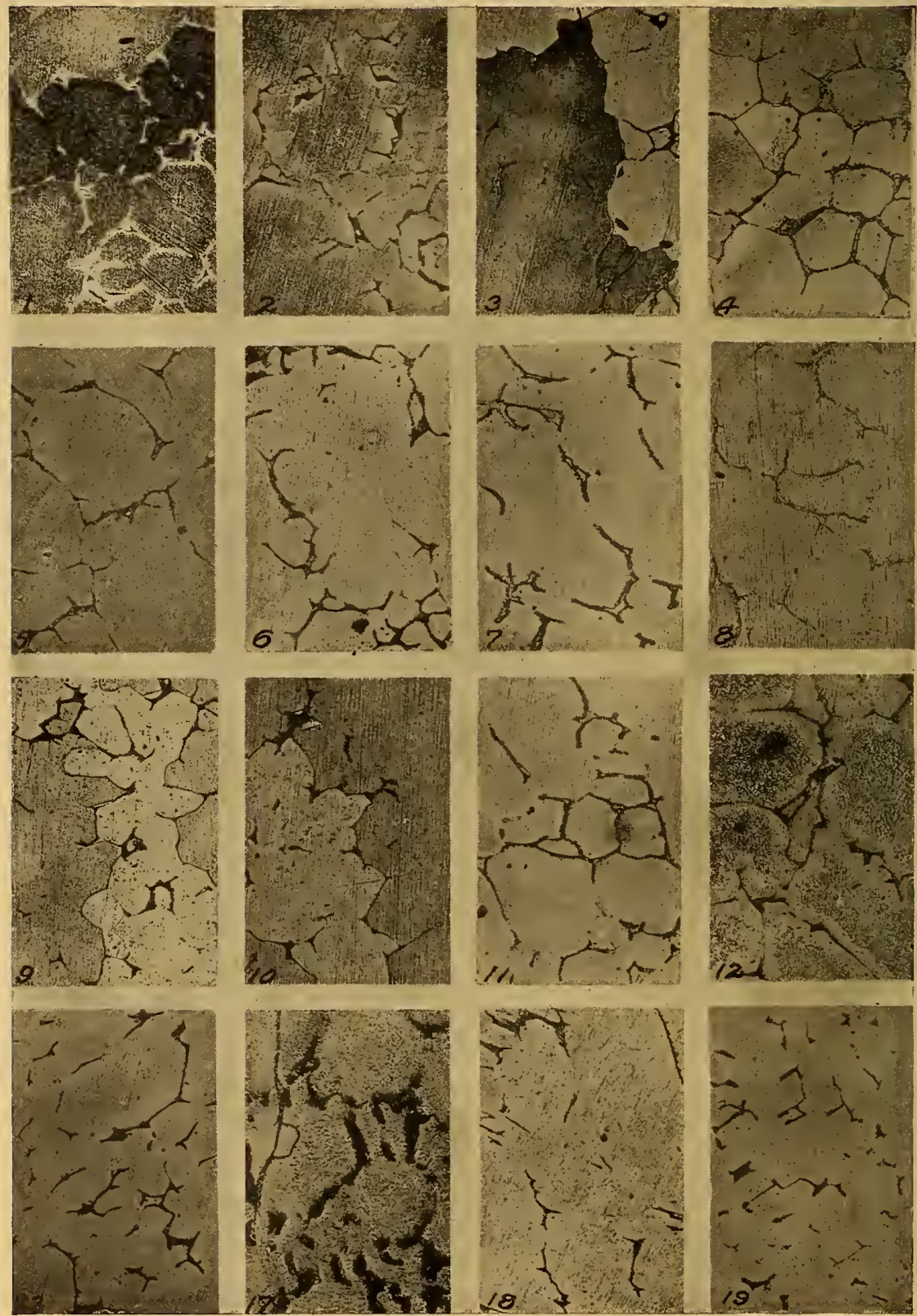

FIG. I7.-Microstructure of cast aluminum bronze (alloy 26, Table I) illustrating the etching characteristics of the alloy. $\times 100$

The number on each micrograph indicates the etching reagent used (Table 2). 
The following materials (Table $\mathrm{I}$ ) were used as representative of the different forms of the metal: Electrolytically deposited nickel, the same after being remelted in vacuo, commercial cast nickel containing oxide, cast nickel which had been deoxidized, hot and cold rolled materials, and a specially treated material termed "manganese nickel." Representative micrographs of cast and rolled nickel are shown in Figs. 18 and 19.

The readiness with which cast nickel will etch depends to a very large extent upon the purity of the metal. Electrolytic nickel remelted in vacuo was found to etch with very much more difficulty than the commercial cast metal. It was also noted for several different specimens that the first time the surface was etched after grinding and polishing the etching period required was usually much longer than that necessary after a slight repolishing of a previously etched surface. It was often necessary to disregard the results of the first etching entirely and depend upon those obtained after the surface had been repolished.

It will be noted from the micrographs (Figs. I 8 and 19) that the addition of an oxidizing agent is often sufficient to make a solution which otherwise would have no appreciable action upon nickel a very fair etching reagent. This does not always answer the purpose, however, and the etching characteristics of nickel appear to be much more "erratic" than do those of copper or even of the alloys of nickel.

One of the more satisfactory reagents for producing a plain etching consists of nitric acid diluted with acetic acid and has been described by Merica. ${ }^{4}$ The most satisfactory reagent for etching nickel and producing contrast with a minimum amount of pitting was found to be concentrated hydrochloric acid. The use of this acid in concentrated form for etching purposes for developing microstructure of nickel and related alloys is new so far as the authors are aware. The only disadvantage in its use is the long time required. In some cases (Table 3) an etching period of one hour was required to develop the structure satisfactorily. However, one of the principal requirements for etching nickel satisfactorily appears to be a very slow uniform action. A solution of ferric chloride produces results somewhat similar to concentrated hydrochloric acid in a much shorter time but, on the whole, is not so desirable, as the pitting of the specimen is sometimes excessive with this reagent. Hydrochloric acid was found 

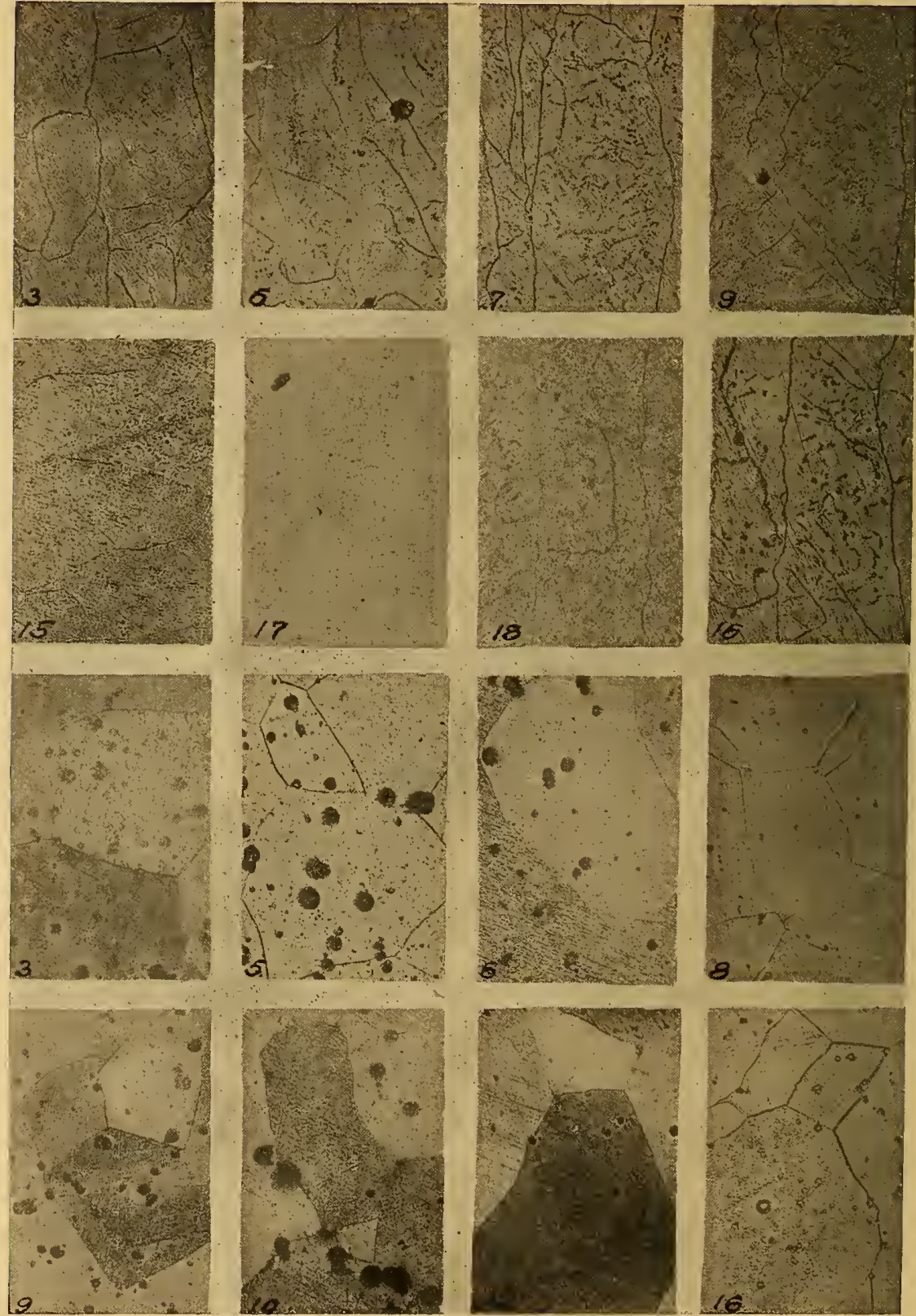

FIG. I8.-Microstructure of cast nickel illustrating the etching characteristicsof this metal.

$$
\times 100
$$

The two upper rows of micrographs are of electrolytic nickel melted in vacuo (specimen 37 , Table 1 ); the two lower rows show the appearance of commercial cast nickel (specimen 29, Table $r$ ).

The number on each micrograph indicates the etching reagent used (Table 2). 

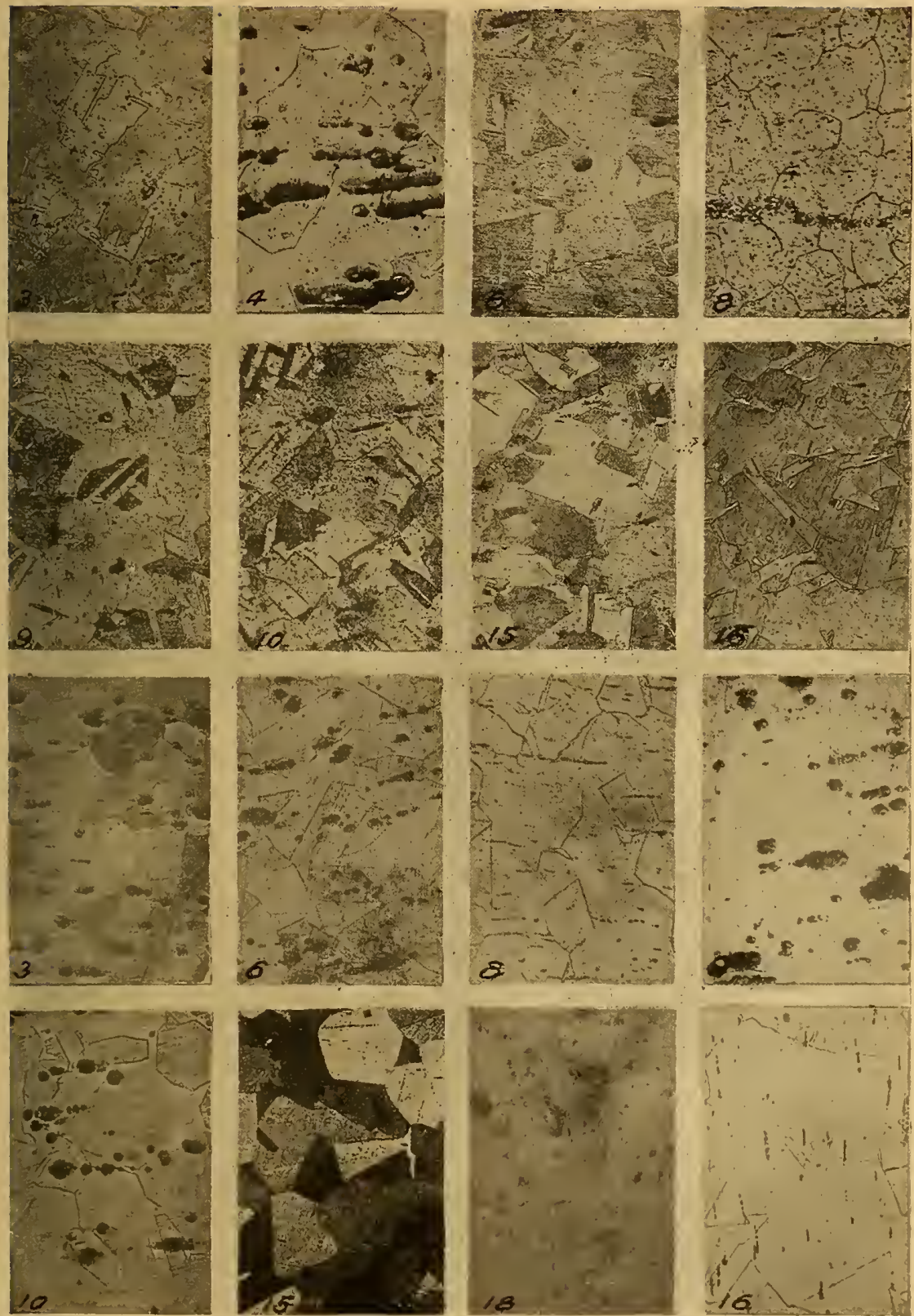

FIG. I9.-Microstructure of rolled nickel after annealing illustrating the etching characteristics of this metal. $\times$ IOO

The two upper rows of micrographs show the structure of sheet nickel (alloy 35. Table I); the two lower rows, manganese-nickel rod (alloy 52 , Table 1 ). The number on each micrograph indicates the etching reagent used (Table 2). 
to be useful also for some of the copper alloys, particularly those in the cast state, and representative micrographs have been given in some of the preceding figures. The period required for etching the copper alloys with hydrochloric acid was, of course, very much shorter than for nickel, a period somewhat less than a minute usually being sufficient.

\section{NICKEL ALLOYS}

The alloys chosen as representative were those in common industrial use and all were of the $\alpha$ type of structure. The list included cupro-nickel, monel metal, nickel brass (nickel silver, formerly German silver) and high nickel steel (invar).

The nickel alloys of the types examined etch very much more readily than does nickel. All of the alloys excepting invar contained a considerable percentage of copper, and the etching characteristics were affected accordingly, so that, though they were not etched so readily as were the copper alloys, they resembled them in their behavior more closely than they did nickel. Practically all the reagents which were found useful for the copper alloys were useful also for the alloys of nickel.

Figs. 20 and $2 \mathrm{I}$ show the characteristic appearance of cupronickel in the cast and the wrought state after etching with various types of reagents. The results produced with the same reagents upon monel metal are shown in Figs. 22, 23, and 24. The micrographs show that the "cored" or dendritic structure of the cupro-nickel is readily revealed by nearly all the reagents used, but not so with monel metal. A point worthy of note concerning the cored structure of nickel alloys is the fact that it appears to be independent of the network of the grain boundaries. It may be noted in some of the micrographs of cast monel metal given that the grain boundary cuts across the dendritic pattern instead of inclosing a complete dendrite entirely within a single grain.

The high nickel "cores" persist after mechanical working of the alloy as "work lines" extending in the direction of rolling or forging. These lines are readily revealed by the vigorously acting reagents, such as nitric acid, and form a very characteristic feature of the microstructure of nickel alloys particularly in the hot-rolled or unannealed state. When an oxidizing reagent was used, there was often a pronounced difference in the intensity of the film produced upon these "work lines" and upon the intermediate streaks, so that the surface had a banded appear- 

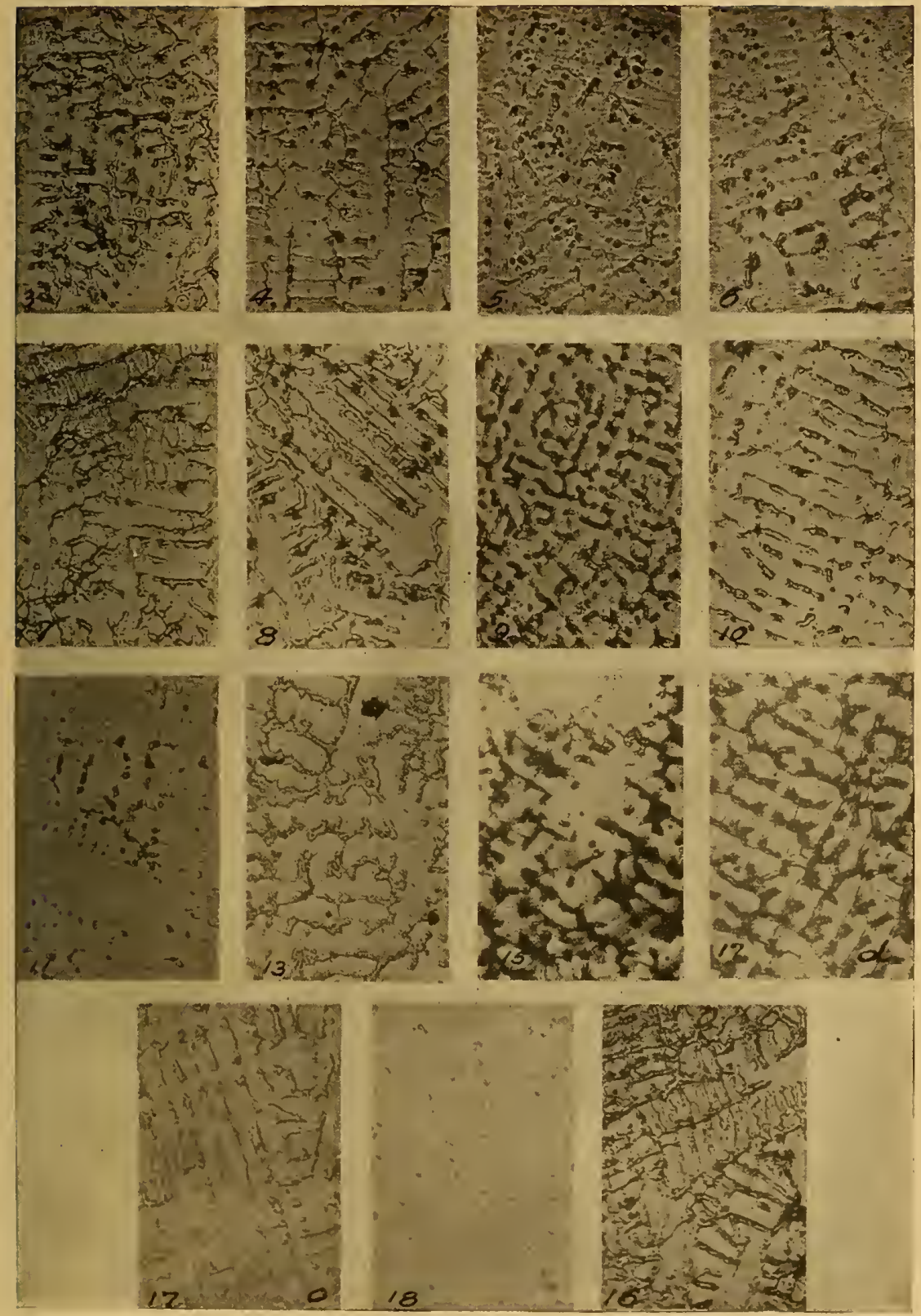

FIG. 20.-Microstructure of cast cupro-nickel (alloy 38 , Table I) illustrating the etching characteristics of the alloy. $\times 100$

The number on each micrograph indicates the ctching reagent (Table 2 ) used. In micrograph I7, $a$ indicates "directly in oxygen current"; 0 "ontside oxygen current." 

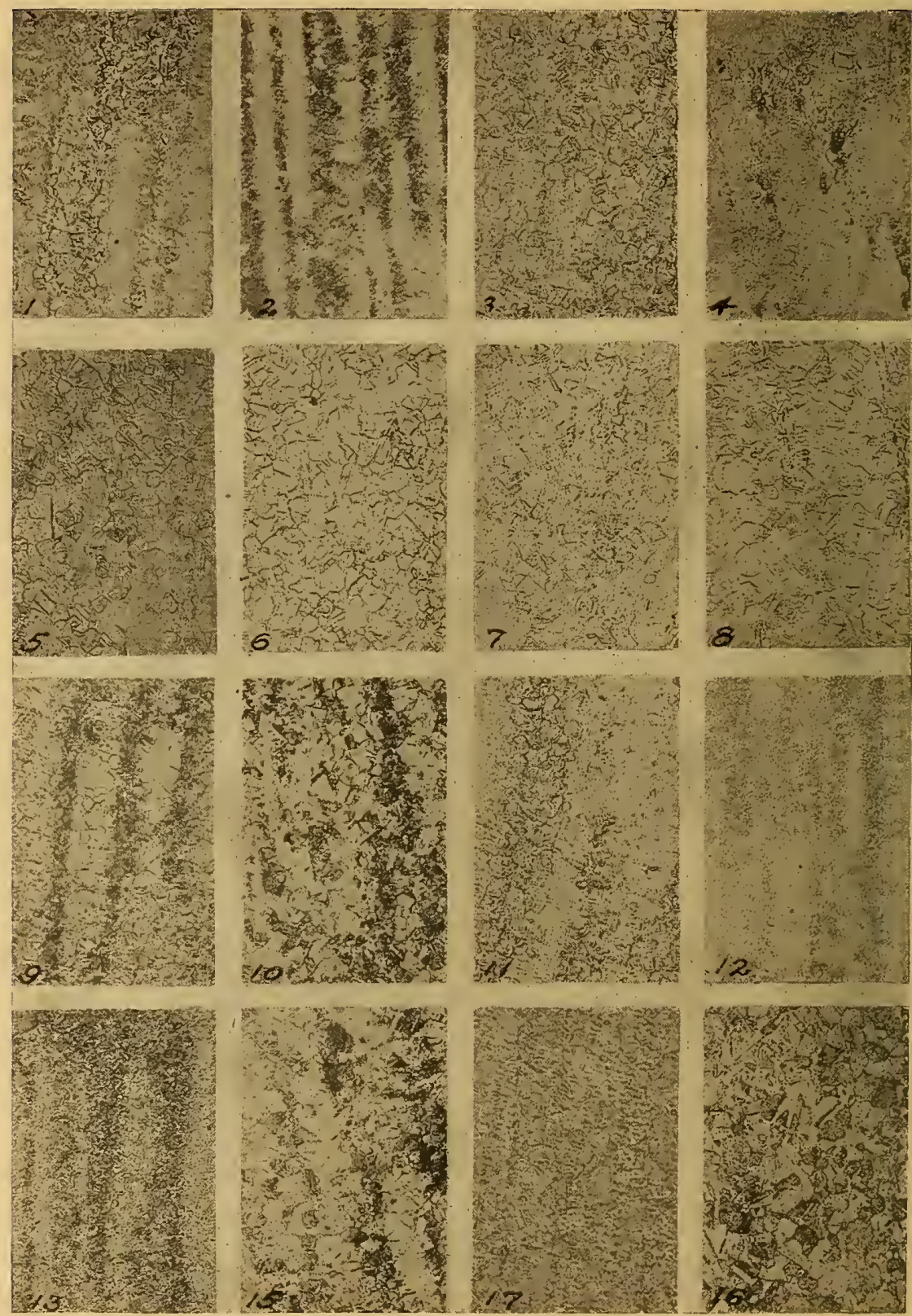

FIG. 21.-Microstructure of cold rolled cupro-nickel sheet (alloy' 44, Table I) illustrating the etching characteristics of the material. $\times 100$

The number on each micrograph indicates the etching reagent (Table 2) used. 

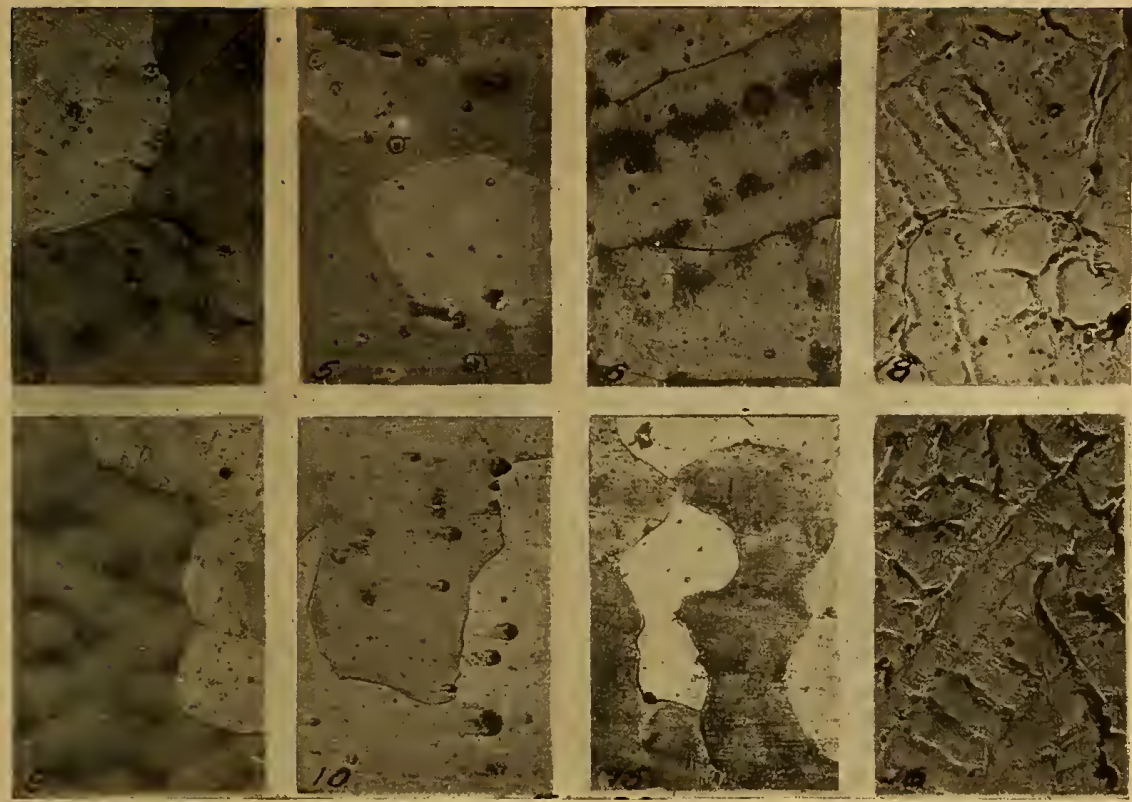

FIG. 22.-Microstructure of cast monel metal (alloy 32, Table I) illustrating the etching characteristics of the metal. $\times 100$

The number on each micrograph indicates the etching reagent (Table 2 ) used.
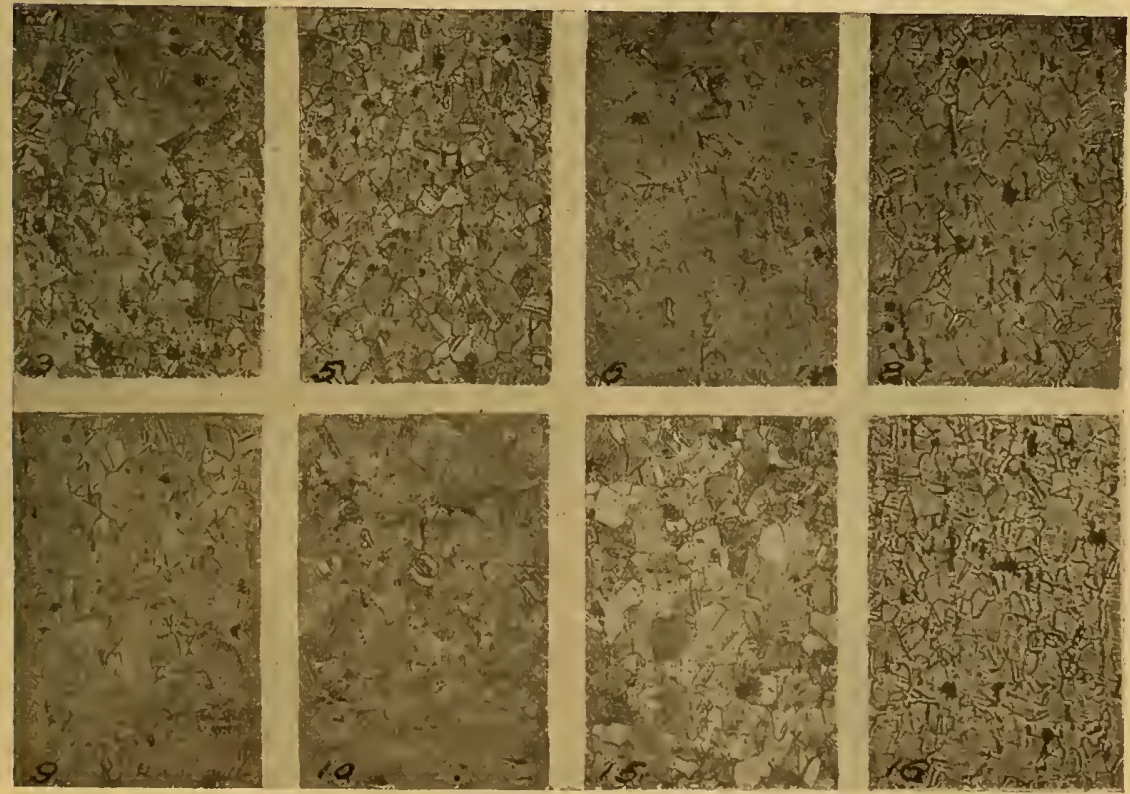

FIG. 23.-Microstructure of cold-draun monel metal rod (alloy 34, Table I). X

The number on each micrograph indicates the etching reagent (Table 2) used. 
ance though otherwise unetched. This was sometimes very pronounced when oxygen was passed through the etching solution, as is shown in Fig. 24.

Figs. 25 and 26 show the results obtained with nickel brass (No. 45, Table I) in the cold-rolled state and the same after
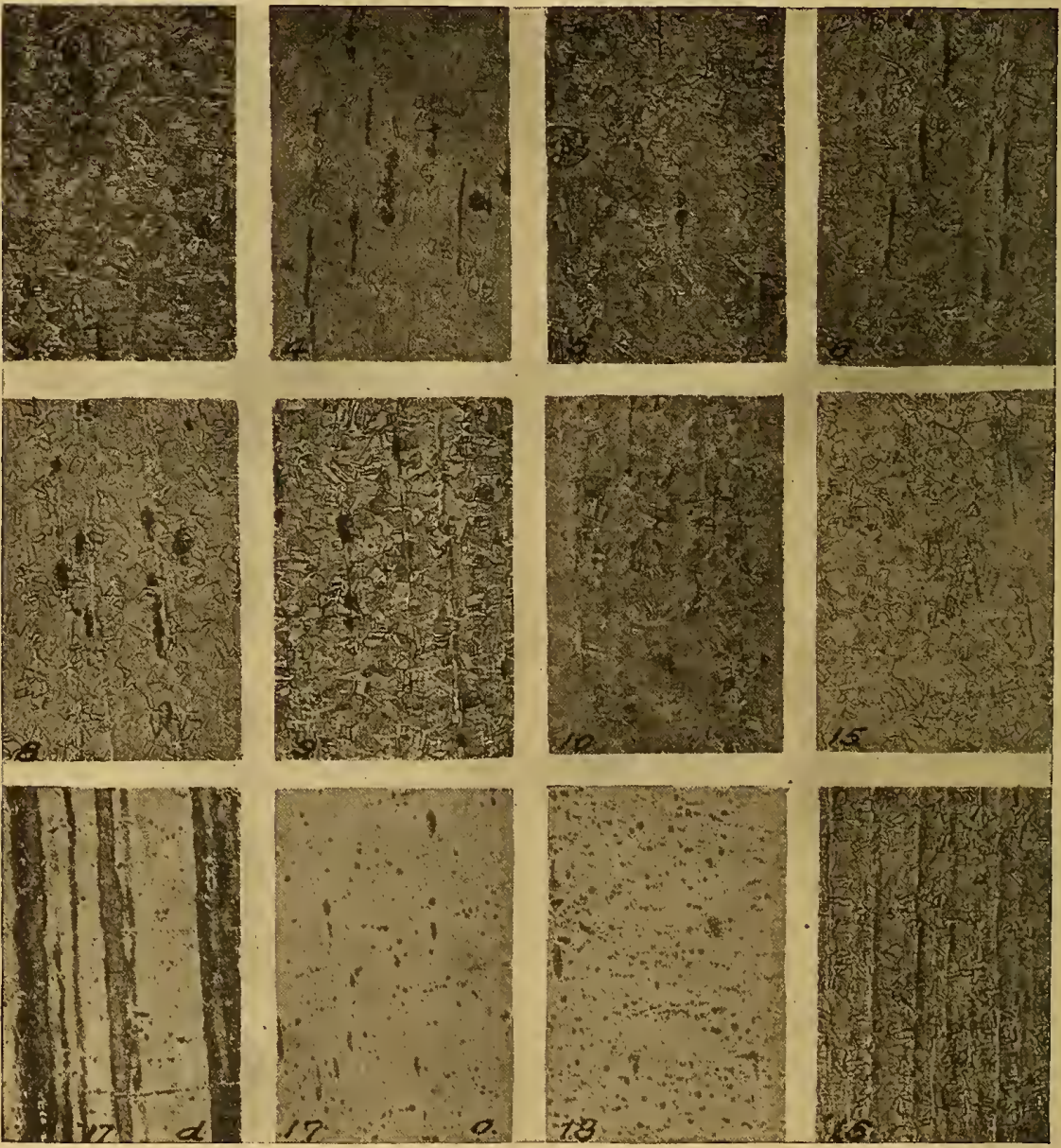

FIG. 24.-Microstructure of hot-rolled monel metal plate (alloy 33, Table I) illustrating the etching characteristics of the alloy. $\times 100$

The number on each micrograph indicates the etching reagent used (Table 2). In micrograph $x_{7}, d$ indicates "directly in oxygen current," o "outside the current oxygen."

annealing. The general behavior of alloys of this group varies with the nickel content. The specimens low in nickel were found, as might be expected, to be very similar to the copperzinc alloys in their etching characteristics although not quite so readily attacked. The contrast produced and the general appearance of the etched surface were quite similar, however. 

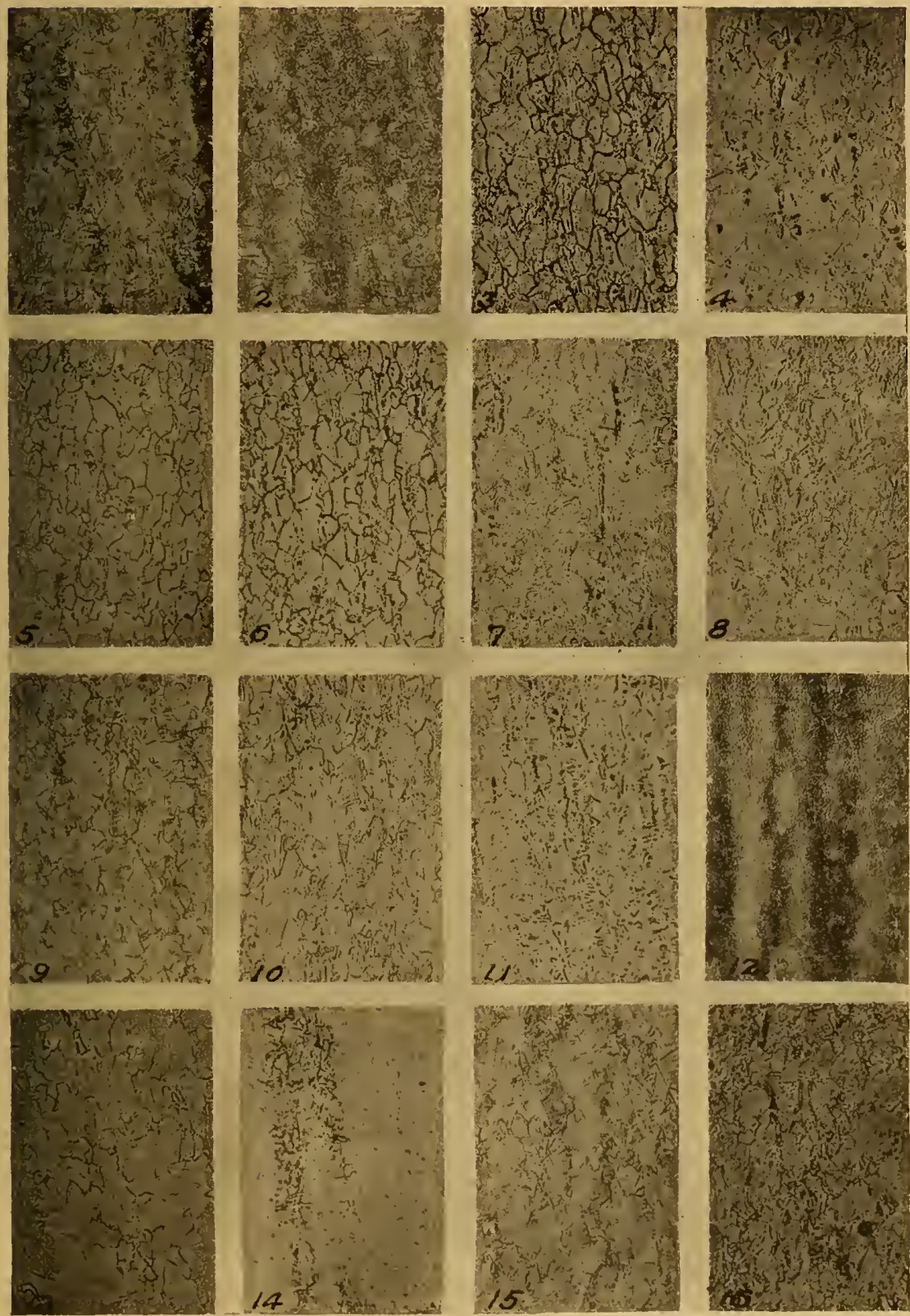

FIG. 25.-Microstructure of cold-rolled nickel-brass sheet (alloy 45, Table I) illustrating the etching characteristics of the alloy. $\times 100$

The number on each micrograph indicates the ctching reagent (Table 2 ) used. 

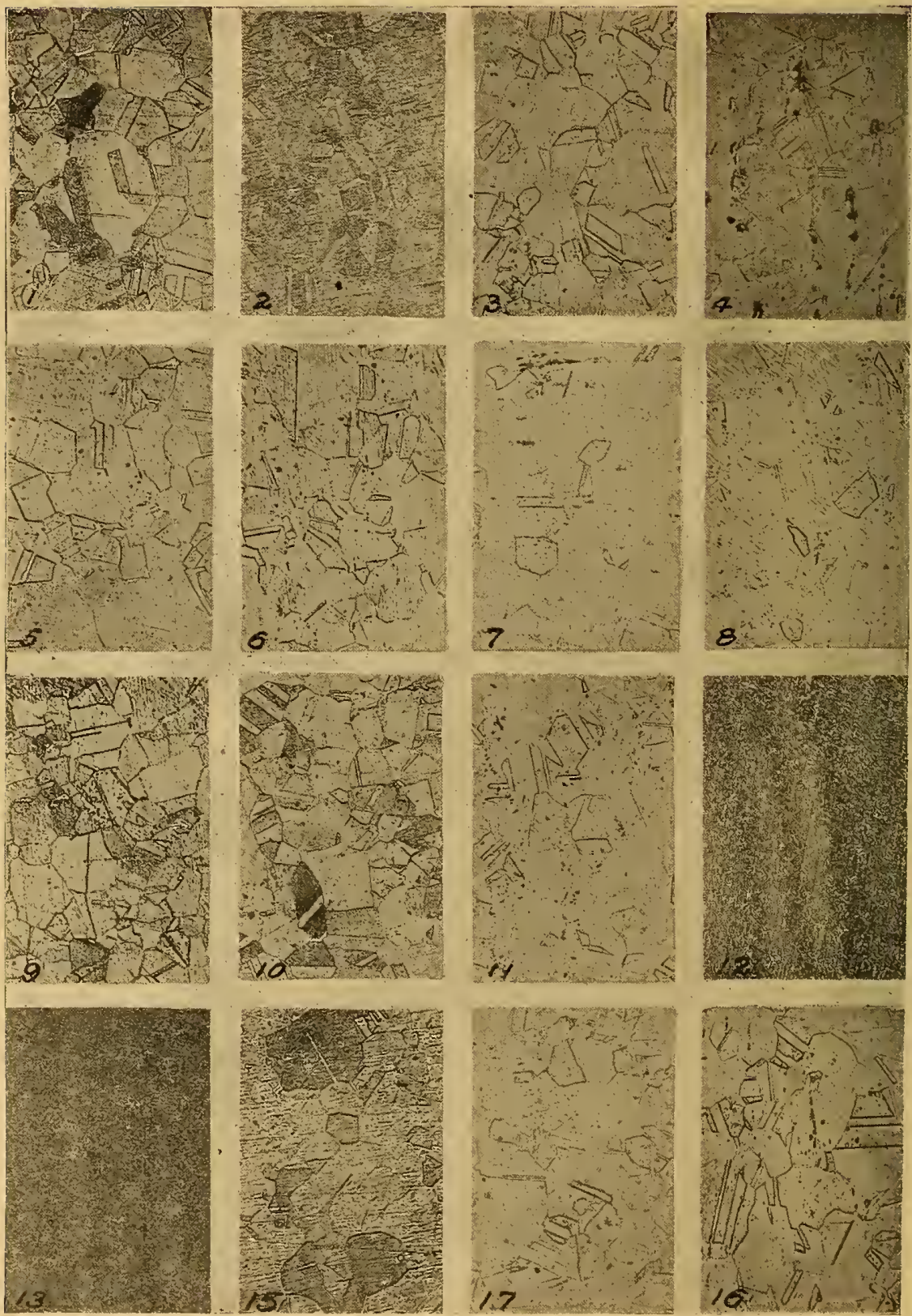

FIG. 26.-Microstructure of annealed nickel-brass sheet (alloy 46, Table I) illustrating the etching characteristics of the alloy. $\times 100$

The number on the micrograph indicates the etching reagent (Table 2 ) used. 


\section{EFFECT OF OXYGEN UPON THE RATE OF ETCHING}

The importance of oxygen in metallographic etching reagents has been previously discussed. ${ }^{5}$ In order to verify and confirm the conclusions which appeared to be justified by the results obtained upon etching copper with reagents through which oxygen was bubbled, specimens representative of the different copper and nickel alloys and of various forms of nickel were etched in a similar manner. Three typical reagents were used-ammonium hydroxide, dilute sulphuric acid, and a solution of ammonium chloride. A stream of oxygen was passed through each after the specimen had been immersed and the bubbles were directed against the surface to be etched.

The results obtained with the $\alpha$ copper alloys, on the whole, confirmed those for copper and need not be considered in detail here. Some typical micrographs are given in Fig. 27. It was noted that when a specimen was etched with ammonium hydroxide and oxygen the most intense attack was in the central portion of the area against which the stream of gas was directed. The best contrast, however, was usually found in the annular portion surrounding the central area where the action was somewhat less vigorous. Those portions of the surface which were not near the oxygen stream remained almost entirely unetched. With dilute sulphuric acid and oxygen the etching action was confined almost entirely to the annular portion, the spot against which the gas was directed remaining bright and unetched. This effect was probably largely the results of mechanical causes. The bubbles of gas in passing through ammonium hydroxide become saturated with ammonia and hence have a pronounced effect; but, since the sulphuric acid is not volatile, a similar condition does not obtain with this reagent, and it is only where the acid solution becomes saturated with oxygen that the metal is attacked. Ammonium chloride and oxygen resembled ammonium hydroxide, although the action was much less intense.

When the duplex copper-zinc alloys were etched by the use of oxygen, the general tendency was for the more soluble (zincrich) constituent to oxidize more readily than the other. Thus, the $\beta$ constituent was found to darken in all reagents much more readily than the $\alpha$. A few exceptions were noted, howeveras, for example, in $\alpha \beta$ brass-in which the oxidation was reversed in the acid solution as compared with the ammoniacal one (Fig. 27). Oxygen as a gas appears to have an almost negligible

- See footnote I. 

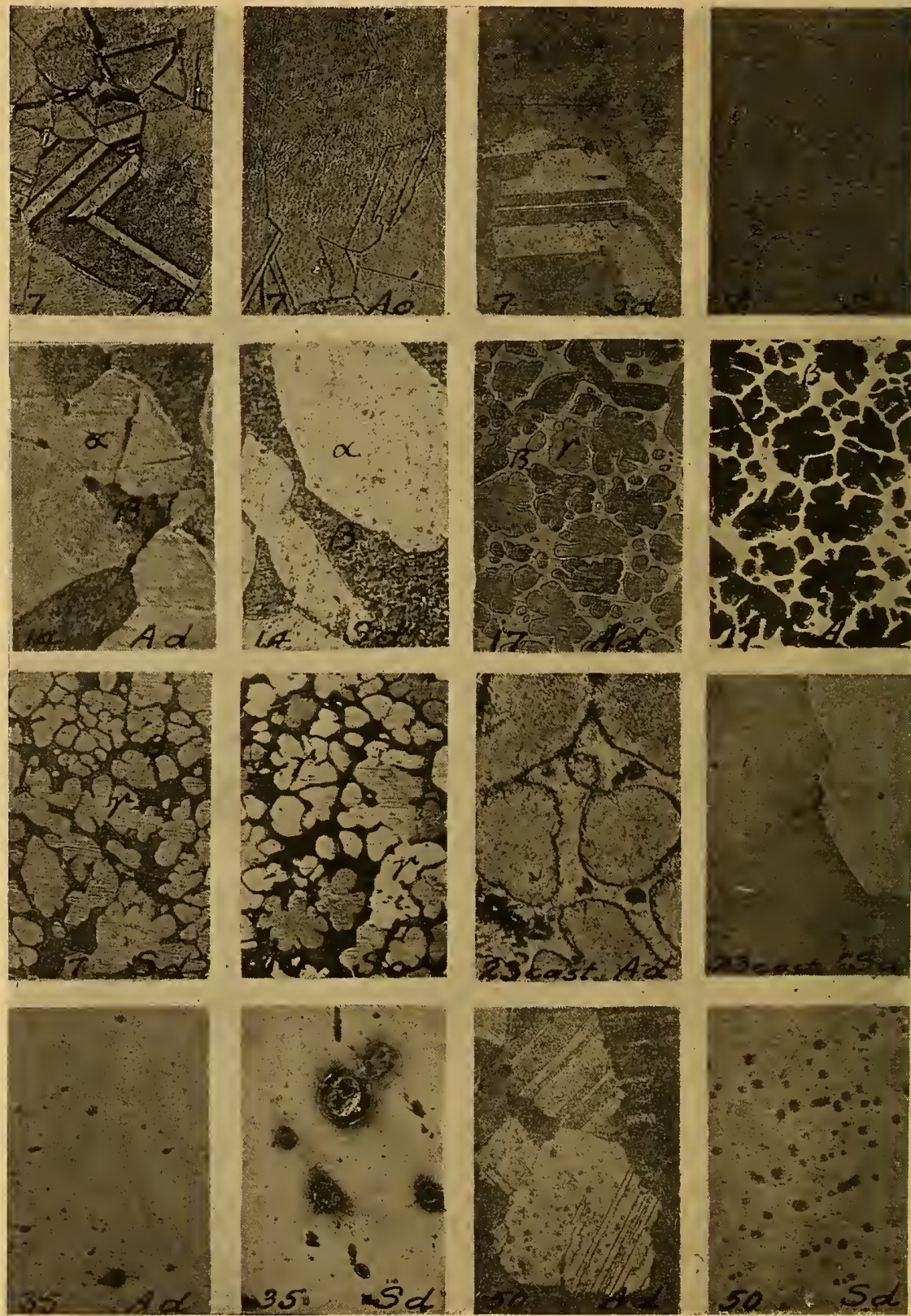

FIG. 27.-Microstructure of various alloys indicating the effect of oxygen gas upon the etching of copper alloys, nickel, and nickel brass. $X 100$

The number on each micrograph indicates the alloy (Table $I$ ). The etching solution is shown on each micromraph. $A$ indicates concentrated ammonium hydroxide; $S$ dilute sulphuric acid; $d$ directly in the oxygen current; $o$ outside the oxygen current. 
influence upon the etching of nickel. The action of sulphuric acid was found to be slightly intensified on account of the attack by the acid on the inclusions in the metal and the formation of pits. The action of ammonium hydroxide and oxygen is very slight and may be disregarded entirely. The behavior of cupronickel and monel metal was very similar to that of nickel under the same conditions. These results are of importance from a practical viewpoint in that they demonstrate in a striking and simple manner the noncorrodibility of these materials.

The nickel brasses were found to be etched very appreciably by ammonium hydroxide and oxygen. Sulphuric acid and oxygen, however, have but little effect upon them.

\section{SUMMARY}

I. This article constitutes the second part of the general investigation of metallographic etching reagents in progress at this Bureau. It is closely related to the one already published on copper in the methods employed and results obtained. The following materials were used: Copper alloys, including brasses, bronze, and aluminum bronze; nickel; and the $\alpha$ alloys of nickel, monel metal, cupro-nickel, and nickel brass.

2. The results of some further experimental work are given to show the importance of films in producing contrast in etching. Oxide and sulphide films were used, and it was shown by separating the etching and the filming operations that films varying in thickness on the individual crystals are produced by certain reagents, giving rise to "contrast." The better understood method for producing contrast by a differential roughening of the crystals upon etching is also illustrated.

3 . The $\alpha$ copper alloys closely resemble copper in their general behavior upon etching and in the character of the results produced. The addition of tin to brass appears to render it slightly less responsive to etching reagents than the same alloy without tin. Aluminum bronze in the rolled condition was the most unsatisfactory of the copper allays examined to etch. A series of copper-zinc alloys representative of all the types of structure in this series was examined. The alloys rich in zinc resemble this metal in their etching characteristics more than they do the copper-rich alloys, in that highly oxidizing etching reagents do not appear to be necessary for the successful etching of the alloy. 
4. Nickel, particularly when of high purity, is etched with considerable difficulty. Oxidizing acids, such as nitric, and acids to which strong oxidizers had been added, were found effective for a quick etching. For producing a contrast etch pattern with freedom from pitting a long immersion in concentrated hydrochloric acid was found to give excellent results.

5. Of the $\alpha$ nickel alloys examined monel metal and cupronickel were found to resemble nickel in their etching properties though they etched more readily. The nickel brasses (nickel silver) resemble the $\alpha$ copper alloys in many respects and were readily etched by the reagents used for the brasses and bronzes.

6 . The copper alloys behave very similarly to copper in their behavior toward etching reagents through which oxygen was bubbled. They were readily etched by reagents-ammoniacal, acid, or neutral-which otherwise would have but slight effect upon them provided a stream of oxygen was passed through the solution while the specimen was immersed. Nickel was found not to be affected materially in its rate of etching by the use of oxygen gas except in the degree of pitting produced in some specimens. Cupro-nickel and monel metal resemble nickel in this respect, and the nickel brasses are somewhat like the copper alloys. They respond to the ammoniacal solutions containing oxygen though not to acid solutions and oxygen.

7. The large number of microscopic examinations which the investigation has necessitated, of which it is possible to present only a relatively small number of the micrographs, has rendered the summarizing of the results a rather difficult matter. Only the more obvious and general features have been discussed.

Washington, August 26, r $92 \mathrm{r}$. 